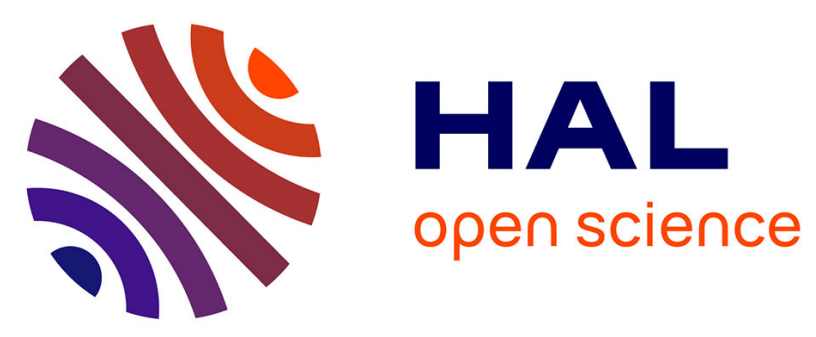

\title{
Chain Entropy Beats Hydrogen Bonds to Unfold and Thread Dialcohol Phosphates inside Cyanostar Macrocycles To Form [3]Pseudorotaxanes
}

Rachel Fadler, Abdelaziz Al Ouahabi, Bo Qiao, Veronica Carta, Niklas König, Xinfeng Gao, Wei Zhao, Yankai Zhang, Jean-François Lutz, Amar Flood

\section{To cite this version:}

Rachel Fadler, Abdelaziz Al Ouahabi, Bo Qiao, Veronica Carta, Niklas König, et al.. Chain Entropy Beats Hydrogen Bonds to Unfold and Thread Dialcohol Phosphates inside Cyanostar Macrocycles To Form [3]Pseudorotaxanes. Journal of Organic Chemistry, 2021, 86 (6), pp.4532-4546. 10.1021/acs.joc.0c02887 . hal-03201717

\section{HAL Id: hal-03201717 https://hal.science/hal-03201717}

Submitted on 30 Nov 2021

HAL is a multi-disciplinary open access archive for the deposit and dissemination of scientific research documents, whether they are published or not. The documents may come from teaching and research institutions in France or abroad, or from public or private research centers.
L'archive ouverte pluridisciplinaire HAL, est destinée au dépôt et à la diffusion de documents scientifiques de niveau recherche, publiés ou non, émanant des établissements d'enseignement et de recherche français ou étrangers, des laboratoires publics ou privés. 


\section{Chain Entropy Beats Hydrogen Bonds}

\section{to Unfold and Thread Dialcohol Phosphates inside}

\section{Cyanostar Macrocycles to form [3]Pseudorotaxanes}

Rachel E. Fadler, ${ }^{\mathrm{a}}$ Abdelaziz Al Ouahabi, ${ }^{\mathrm{b}}$ Bo Qiao, ${ }^{\mathrm{a}}$ Veronica Carta, ${ }^{\mathrm{a}}$ Niklas F. König, Xinfeng Gao, ${ }^{a}$ Wei Zhao, ${ }^{\text {a }}$ Yankai Zhang, ${ }^{\mathrm{b}}$ Jean-François Lutz, ${ }^{\mathrm{b}}$ Amar H. Flood ${ }^{\mathrm{a}}$

a Department of Chemistry, Indiana University, Bloomington, IN, 47405, USA.

Email: aflood@indiana.edu

${ }^{b}$ Université de Strasbourg, CNRS, Institut Charles Sadron UPR22, Strasbourg, 67034, France

Published in Journal of Organic Chemistry, 86, 4532-4546 (2021)

https://pubs.acs.org/doi/10.1021/acs.joc.0c02887 


\begin{abstract}
:
The recognition of substituted phosphates underpins many processes including DNA binding, enantioselective catalysis, and recently template-directed rotaxane synthesis. Beyond ATP and a few commercial substrates, however, little is known about how substituents effect organophosphate recognition. Here, we examined alcohol substituents and their impact on recognition by cyanostar macrocycles. The organophosphates were disubstituted by alcohols of various chain lengths, dipropanol, dihexanol, and didecanol phosphate, each accessed using modular solid-phases syntheses. Based on the known size-selective binding of phosphates by $\pi$ stacked dimers of cyanostars, threaded [3]pseudorotaxanes were anticipated. While seen with butyl substituents, pseudorotaxane formation was disrupted by competitive $\mathrm{OH} \bullet \bullet \mathrm{O}^{-}$hydrogen bonding between both terminal hydroxyls and the anionic phosphate unit. Crystallography also showed formation of a backfolded propanol conformation resulting in 8-membered ring and a perched cyanostar assembly. Motivated by established entropic penalties accompanying ring formation, we reinstated [3]pseudorotaxanes by extending the size of the substituent to hexanol and decanol. Chain entropy overcomes the enthalpically favored $\mathrm{OH} \bullet \bullet \mathrm{O}^{-}$contacts to favor random-coil conformations required for seamless, high-fidelity threading of dihexanol and didecanol phosphates inside cyanostar. These studies highlight how chain length and functional groups on phosphate's substituents can be powerful design tools to regulate binding and control assembly formation during phosphate recognition.
\end{abstract}




\section{Introduction}

Substituent-mediated recognition of organophosphates underpins processes across biology $y^{1}$ and chemistry ${ }^{2}$ yet the role of the substituents is poorly understood. ${ }^{3}$ The biorecognition of oligonucleotides, ${ }^{4,5} \mathrm{R}^{1}-\mathrm{PO}_{4}^{-}-\mathrm{R}^{1}$ ( $\mathrm{R}^{1}$ = hydroxyl-substituted ribose/deoxyribose sugars), and phospholipids, ${ }^{6,7} \mathrm{R}^{3}-\mathrm{PO}_{4}{ }^{-}-\mathrm{R}^{4}$ (e.g., $\mathrm{R}^{3}=$ ester-linked fatty acids, $\mathrm{R}^{4}=4^{\mathrm{o}}$ ammonium) are critical for life $\mathrm{e}^{8-11}$ and human health ${ }^{12}$ while chiral phosphates, $\mathrm{R}^{5}-\mathrm{R}^{5^{*}}-\mathrm{PO}_{4}^{-}$, (e.g., $\left.\mathrm{R}^{5}-\mathrm{R}^{5^{*}}=\mathrm{BINOL}\right)$ enable organic catalysis. ${ }^{13,14}$ Synthetic organophosphates ${ }^{15,16}$ are also functional targets, such as, designer polyphosphates for information storage, ${ }^{17-19}$ self-assembly ${ }^{20-23}$ and templates ${ }^{24}$ for rotaxane synthesis. ${ }^{25}$ Despite this broad diversity of usage, and beyond dihydrogen phosphate anions $^{26-31}\left(\mathrm{H}_{2} \mathrm{PO}_{4}^{-}\right)$most studies of organophosphate recognition have focused on ATP. ${ }^{32-34}$ Recognition targets are growing with more aimed at phosphorylated biomolecules, ${ }^{35-39}$ phosphaterich phytate,${ }^{40-42}$ dyes,${ }^{43}$ insecticides,${ }^{44}$ herbicides,${ }^{45}$ neurotoxins,${ }^{46}$ and phosphoryl nerve agents.${ }^{47-}$ ${ }^{50}$ However, the binding of disubstituted phosphates $\left(\mathrm{R}-\mathrm{PO}_{4}{ }^{-}-\mathrm{R}\right){ }^{51,52}$ where $\mathrm{R}=$ alkyl,${ }^{53}$ benzyl, ${ }^{54}$ phenyl, ${ }^{55}$ and propargyl, ${ }^{25}$ is rare, which is limited by the synthetic difficulty for disubstituted organophosphate. One strategy to diversify organophosphates to help understand their recognition is using modular, automated, ${ }^{56}$ solid-phase ${ }^{57}$ syntheses derived from phosphoramidite chemistry. ${ }^{58}$ The resulting organophosphates possess terminal hydroxyl units (Figure 1a). While useful as functional groups for further functionalization, the role of hydroxyls and linking alkyl chains on binding is unknown. We address the recognition of this class of organophosphates using macrocyclic cyanostars (CS, Figure 1b), ${ }^{24-26}$ which are size-matched to phosphate anions and enable programmed formation of threaded structures (Figure 1c). We find, however, that hydroxyls $(-\mathrm{OH})$ hydrogen bond to and fold up the organophosphate (Figure 1d) to compete with pseudorotaxane formation, which can only be overcome using synthetic control of chain length to access the many conformations that turn on the entropy penalty of ring formation ${ }^{59-61}$ (Figure 2). 
(a)

$$
\text { Organophosphates }
$$

Dibutyl

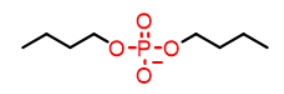

Dipropanol

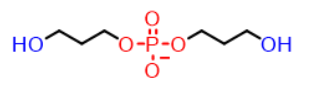

Dihexanol

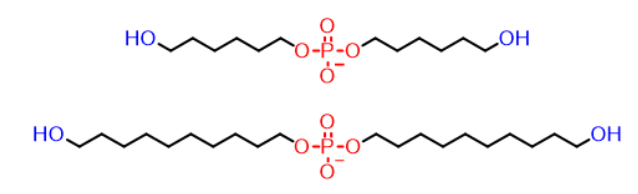

Didecanol (b) Cyanostar

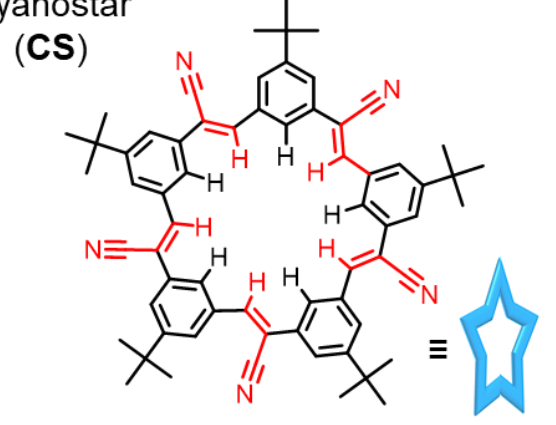

(c)

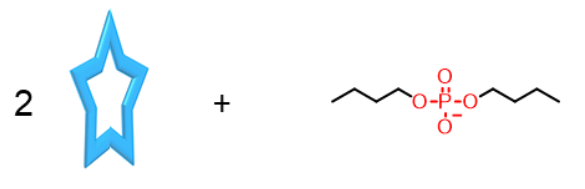

(d)

\begin{tabular}{|c|c|c|c|}
\hline & Anti & 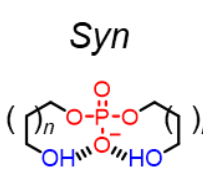 & 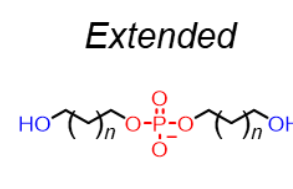 \\
\hline$\Delta H$ & Favored & Unfavored & Disfavored \\
\hline$\Delta S$ & Unfavored & Unfavored & Favored \\
\hline
\end{tabular}

Figure 1. (a) Structures of dibutyl, dipropanol, dihexanol and didecanol phosphate, and (b) the cyanostar macrocycle. (c) Dibutyl phosphate threads inside two $\pi$-stacked cyanostars to form a [3]pseudorotaxane stabilized by $20 \mathrm{CH} \bullet \bullet \mathrm{O}^{-}$hydrogen bonds. (d) Representative folding equilibria of alcohol-substituted phosphates involve a balance between formation of two $\mathrm{OH} \bullet \bullet \mathrm{O}^{-}$hydrogen bonds into folded cyclic structures (anti/syn) and random-coil extended structures.

Studies of the receptor-mediated binding and recognition of disubstituted organophosphates is rare. ${ }^{51,52}$ The binding of dibenzyl phosphate $\left(\mathrm{Bz}-\mathrm{PO}_{4}^{-}-\mathrm{Bz}\right)$ by doubly charged bis(alkylguanidinium) receptors ${ }^{54}$ was studied to establish the effect of the phosphate's charge relative to monophenyl phosphate $\left(\mathrm{Ph}-\mathrm{PO}_{4}{ }^{2-}\right)$ but differences between substituents were 
not examined. The number of organic substituents on organophosphates was shown to impact binding to cationic sapphyrin macrocycles ${ }^{62}$ with $\mathrm{H}_{2} \mathrm{PO}_{4}^{-}$preferring 1:1 stoichiometry while the monobasic mono- and di-phenyl substituted phosphates favored 1:2 structures in the solid state. These 1:2 assemblies had different packings, which were attributed to differences in the number of hydrogen bond donors, the overall shape of the anion, and crystal growing effects. A variation in stoichiometry with substitution was also seen in the binding to cyanostar macrocycles. ${ }^{26,63}$ Therein, with $\mathrm{H}_{2} \mathrm{PO}_{4}^{-}$alone, ${ }^{26}$ formation of divergent anti-electrostatic hydrogen bonds $(\mathrm{AEHBs})^{64}$ between multiple anions produced a mixture in solution composed of higher-order complexes with a range of cyanostar-anion ratios $(4: 3,3: 3,3: 2,2: 2,2: 1)$ depending on the conditions in solution. Phosphates monosubstituted with bulky naphthyl groups ${ }^{63}$ simplified the behavior by forming only a 2:2 species with convergent AEHBs. Disubstituted phosphates cannot support AEHBs and thus dibutyne and dipropyne substituted phosphates formed [3]pseudorotaxanes with cyanostar macrocycles ${ }^{25}$ in a $2: 1$ stoichiometry consistent with sizeselective binding of aprotic anions. ${ }^{24}$ The bambusuril macrocycle also has binding preferences for larger anions ${ }^{65}$ but was seen in the solid state to bind 2 equivalents of diethyl phosphate ${ }^{66}$ in a perched geometry with the anions bridged by water molecules. These studies suggest that a substituent's sterics play an important role in the binding of organophosphates.

Despite the diverse roles of disubstituted phosphates, ${ }^{67-69}$ the introduction of hydroxyl functional groups has only been explored when mimicking biocatalysis. The binding of organophosphates was leveraged in studies ${ }^{70-72}$ on the reactivity of the terminal hydroxyl groups toward transesterification of phosphodiesters. In those cases, most receptors ${ }^{70-74}$ also contained basic sites, e.g., pyridines, imidazoles, hydroxyls, for deprotonating the hydroxyl groups in order 
to accelerate the hydrolysis of the organophosphates. The role of terminal hydroxyl $(-\mathrm{OH})$ groups on recognition properties therefore remain untested.

(a) Many Conformations

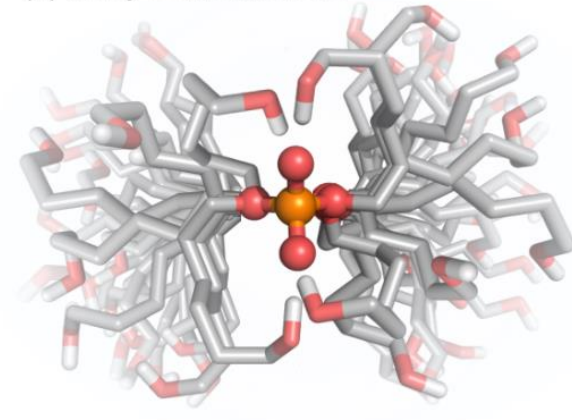

(b) One of many folded conformations

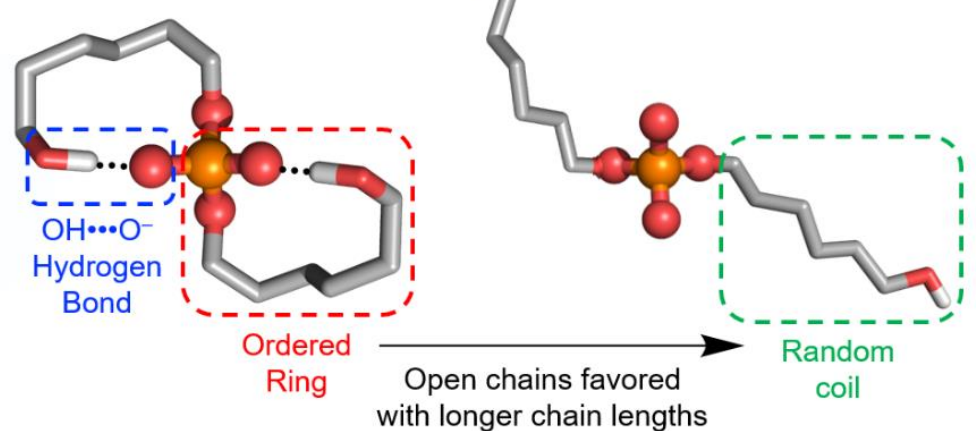

Figure 2. Models of the conformations of the dihexanol phosphate guest showing (a) many possible conformations, (b) one folded conformation and (c) one of many extended, random-coil conformations favored with longer chains.

Hydroxyl groups known to be strong hydrogen bond donors ${ }^{75}$ capable of anion binding, ${ }^{76-}$ 78 and while interactions with phosphates are expected, ${ }^{79}$ their role has not been studied. Similar interactions have been seen but between $\mathrm{NH}$ hydrogen bond donors and phosphates in receptors. ${ }^{80}$ The ability of phosphate to act as a base $\mathrm{H}^{14,81}$ and deprotonate phenol $\mathrm{OH}$ groups may have discouraged further study of $\mathrm{OH} \bullet \bullet \mathrm{O}^{-}$motifs. ${ }^{82}$ Nevertheless, and not unsurprisingly, evidence for hydrogen bonds between hydroxyl units and phosphates is seen in other areas of chemistry ${ }^{83,84}$ and biology. ${ }^{85,86}$ Putative intermolecular hydrogen bonds between hydroxyl-substituted substrates and chiral phosphate ligands $\left(\mathrm{R}^{*}=\mathrm{PO}_{4}^{-}\right)$were invoked in the enantioselective fluorination of phenols. ${ }^{87}$ Intramolecular $\mathrm{OH} \bullet \bullet \mathrm{O}^{-}$hydrogen bonds between hydroxyls and phosphates were observed in a crystal structure of oligonucleotides ${ }^{88}$ between ribose and the phosphate backbone. 
Interestingly, phosphorylation was used as a switch to fold up an intrinsically disordered protein ${ }^{89}$ and is shown with NMR spectroscopy to operate by a threonine $\mathrm{OH}$ hydrogen bonding to the phosphoryl site. Based on these precedents, hydroxyl groups would be expected to hydrogen bond with anionic phosphates to impact their recognition by regulating their structures (Figure 2).

Herein, we evaluate the role of hydroxyl endgroups on the binding of disubstituted organophosphates with cyanostar macrocycles. We do not know if the competition for phosphate posed by two (2) strong intramolecular $\mathrm{OH} \bullet \bullet \mathrm{O}^{-}$hydrogen bonds will displace the many (20) weak $\mathrm{CH} \cdot \cdots \mathrm{O}^{-}$hydrogen bonds formed inside the $2: 1$ intermolecular complex with cyanostar. In the latter, large anions ${ }^{24}$ with the same size as disubstituted phosphates are usually bound as a 2:1 complex with high affinities $\sim 10^{12} \mathrm{M}^{-2}$. To help evaluate this competition, we designed a series of organophosphates. As a control, the binding of dibutyl phosphate bearing just alkyl chains was confirmed to form a threaded [3]pseudorotaxane. Isosteric introduction of hydroxyl groups in dipropanol phosphate generated additional equilibria that competed with [3]pseudorotaxane formation. A perched 2:2 assembly was observed in the crystal structure with $\mathrm{OH} \bullet \bullet \mathrm{O}^{-}$hydrogen bonding from the two hydroxyl groups to the phosphate. Computational modelling revealed the strong enthalpic preferences for the formation of the $\mathrm{OH} \cdots \mathrm{O}^{-}$hydrogen bonds with concomitant generation of two 8-membered intramolecular rings. Among the many conformations possible (Figure 2a), the ones folded into a cycle (Figure 2b) regulated the recognition. Thus, we leveraged the well-known impact of entropy on ring formation by lengthening the alkyl chain (Figure 2c) to lower the probability of forming the back-folded ${ }^{90-92}$ conformations. Using dihexanol and didecanol organophosphates, high-fidelity [3]pseudorotaxane formation was reinstated. These findings show how organic substituents can play significant roles in organophosphate recognition as well as being subject to manipulation for guiding self-assembly towards desirable products. 


\section{Results and Discussion}

\section{Dibutyl Phosphate-Cyanostar [3]Pseudorotaxanes}

In the simplest case, cyanostar forms [3]pseudorotaxanes as threaded 2:1 cyanostar:anion complexes with dialkyl substituted organophosphates. A ${ }^{1} \mathrm{H}$ NMR titration monitoring addition of cyanostar to dibutyl phosphate $\left(4: 1 \mathrm{CD}_{2} \mathrm{Cl}_{2}: \mathrm{CD}_{3} \mathrm{CN}\right.$, Figure 3a) shows slow-exchange peaks. Based on the $\alpha$ methylene protons $\left(\mathrm{H}_{\mathrm{f}}\right)$ on the organophosphate, we see conversion at just over two equivalents (Figure $3 b$ ) to a 2:1 cyanostar-phosphate assembly with characteristic peaks. ${ }^{24,25}$ Specifically, diastereomeric pairs (e.g., $\mathrm{H}_{\mathrm{b}}$ and $\mathrm{H}_{\mathrm{b}}$ ) only emerge when the bowl-shaped $M$ - and $P$ handed cyanostars (Figure S28) form a $\pi$-stacked dimer. ${ }^{24}$ We observe $83 \%$ of the meso $\left(M P, \mathrm{H}_{\mathrm{b}}\right)$ and $17 \%$ of the chiral $\left(M M\right.$ plus $P P, \mathrm{H}_{\mathrm{b}}$ ) diastereomers (Figure $\left.3 \mathrm{a}\right){ }^{25}$ These percentages are similar to studies using dipropargyl phosphate (90\% meso, $10 \%$ chiral). ${ }^{24}$

Formation of a threaded [3]pseudorotaxane structure was further confirmed by 2D NMR studies. ${ }^{1} \mathrm{H}-{ }^{1} \mathrm{H}$ ROESY (Figure $4, \mathrm{CD}_{2} \mathrm{Cl}_{2}$ ) shows cross peaks between the cyanostar's $\mathrm{CH}$ hydrogen-bonding protons on the macrocycle's interior, $H_{a}$ and $H_{d}$, and the phosphate's $\alpha$ methylene protons, $\mathrm{H}_{\mathrm{f}}$. The threaded architecture is also supported by the change in chemical shift of the phosphate's methylene, $\mathrm{H}_{\mathrm{f}}$ (Figure 3a). A 1-ppm downfield shift upon complexation with cyanostar is consistent with being close to the plane of the cyanostar. ${ }^{24,25}$ Observation of a threaded [3]pseudorotaxane in dichloromethane provides us with a foundation for testing the effects of the terminal hydroxyl groups on its recognition. 
(a)

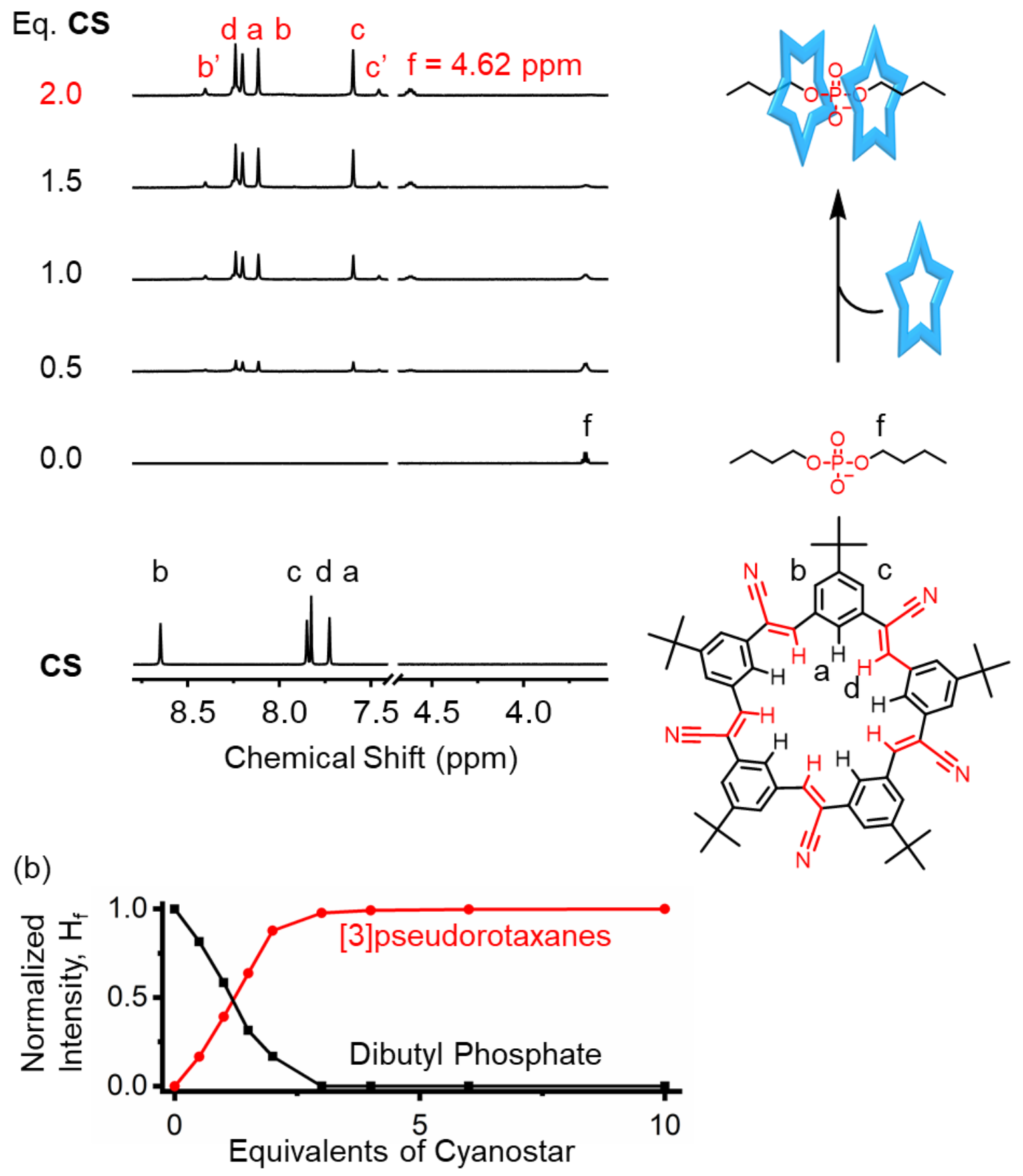

Figure 3. (a) ${ }^{1} \mathrm{H}$ NMR titration of cyanostar into dibutyl phosphate $\left(1 \mathrm{mM}\right.$, in $4: 1 \mathrm{CD}_{2} \mathrm{Cl}_{2}: \mathrm{CD}_{3} \mathrm{CN}$, $298 \mathrm{~K}, 600 \mathrm{MHz}$ ). (b) Normalized peak intensities of uncomplexed phosphate $\left(\mathrm{H}_{\mathrm{f}}\right)$ and [3]pseudorotaxane $\left(\mathrm{H}_{\mathrm{f}}\right)$. 

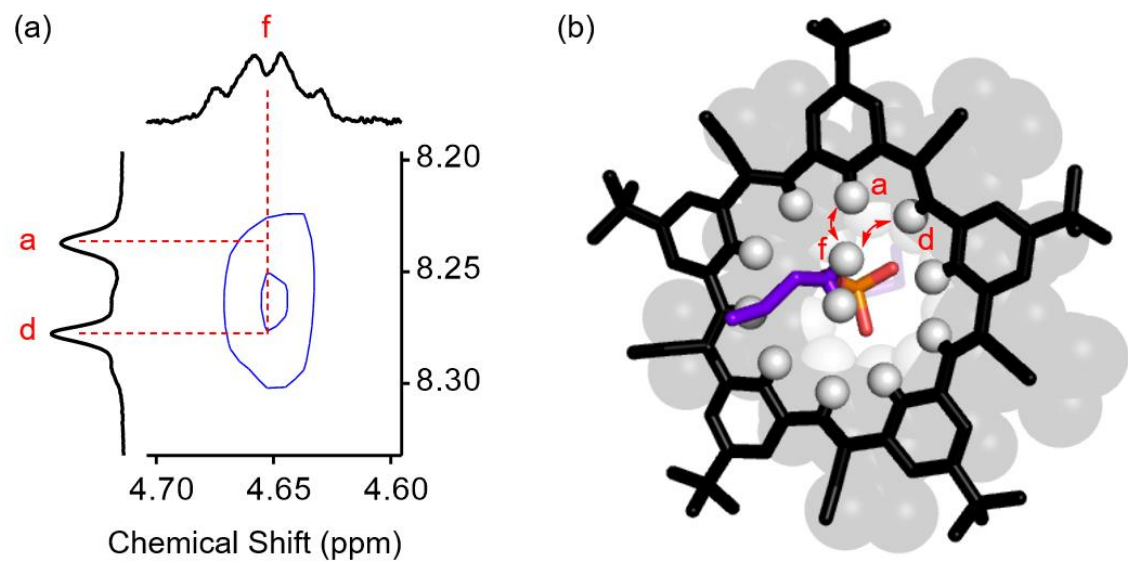

Figure 4. (a) ${ }^{1} \mathrm{H}-{ }^{1} \mathrm{H}$ ROESY of the [3]pseudorotaxane with cyanostar $(1 \mathrm{mM})$ and dibutyl phosphate (0.5 eq) in $\mathrm{CD}_{2} \mathrm{Cl}_{2}(298 \mathrm{~K}, 600 \mathrm{MHz})$ and (b) model of the contacts

\section{Intramolecular Hydrogen Bonds to Phosphate}

An examination of the recognition characteristics of dipropanol phosphate was undertaken starting with a conformational analysis (molecular mechanics, gas phase, Figure S1). As expected, the most favored conformation shows both end groups engaging in $\mathrm{OH} \cdots \mathrm{O}^{-}$hydrogen bonds with the phosphate moiety. The folded conformation forms 8-membered rings between the end groups and two different oxygen atoms on the phosphate in an anti arrangement. There are many anti conformations differing only in the local arrangements of the alkyl chains. The next unique arrangement shows hydrogen bonding from either end to the same oxygen atom to form a syn geometry, which also generated a range of alkyl conformers. All 235 conformations found by molecular mechanics to be less than $40 \mathrm{~kJ} \mathrm{~mol}^{-1}$ had the two hydrogen bonds. The anti and syn structures were further refined by density functional theory (DFT, B3LYP/6-31+G*) and the anti was found to be favored by $+16 \mathrm{~kJ} \mathrm{~mol}^{-1}$ (Figure $5 \mathrm{a}-\mathrm{b}$ ). 
We examined the experimental evidence for the folded conformation in solution by NMR spectroscopy (Figures S23-S25). First, the ${ }^{3} J$ coupling between phosphorous and $\mathrm{H}_{\mathrm{f}}$ protons on the organic backbone was used to examine the conformational changes of the molecule in different solvents. As known from the Karplus equation, ${ }^{93}, 94$ specific conformations display specific coupling constants while random coils display average values. ${ }^{95,} 96$ Using dibutyl phosphate as a model for a random coil, ${ }^{31} \mathrm{P}_{-}{ }^{1} \mathrm{H}_{\mathrm{f}}$ coupling was $6.5 \mathrm{~Hz}$, which is the average of a variety of lowlying conformations. Dipropanol phosphate is anticipated from modelling to be in a compact folded geometry with local conformations accessible. We observe the coupling is $10.8 \mathrm{~Hz}$ indicative of a different average geometry. When the solvent is changed to a methanol mixture to disrupt $\mathrm{OH} \bullet \bullet \mathrm{O}^{-}$hydrogen bonds, we expect a random coil (Figure 5c) and consistently see a coupling constant $(6.3 \mathrm{~Hz})$ that matches dibutyl phosphate. This interpretation is further confirmed by the appearance of the hydroxyl proton peak and the ${ }^{3} J$ coupling between the hydroxyl proton and the $\mathrm{H}_{\mathrm{f}}$ proton observed in aprotic condition, but not in protic condition (Figures S23 and S24). 
(a) Anti Hydrogen Bonding

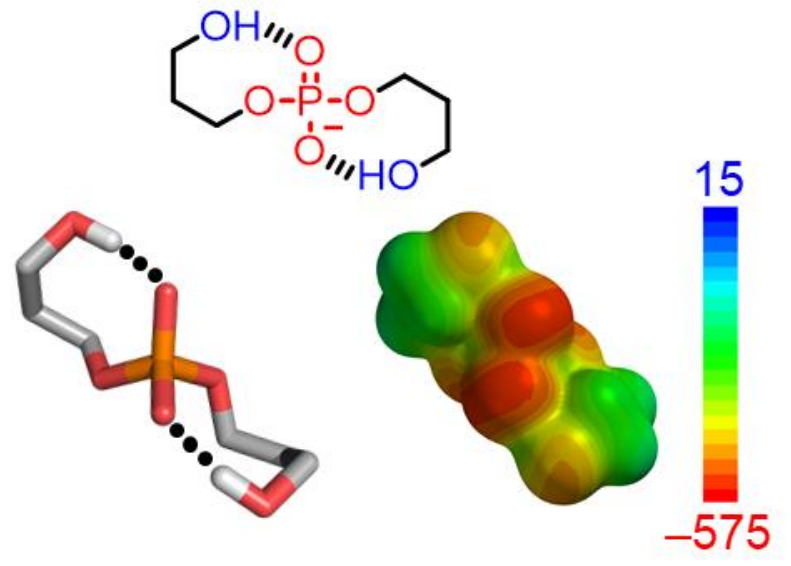

(b) Syn Hydrogen Bonding

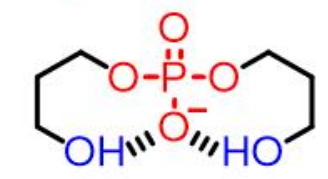

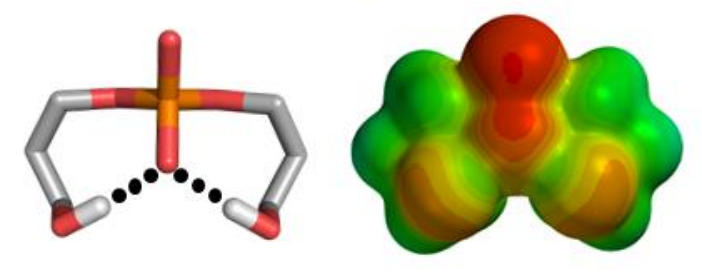

(c)

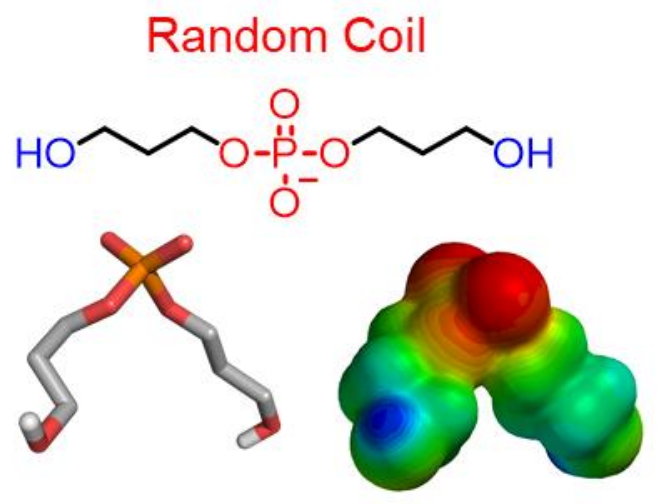

Figure 5. (a) Anti and (b) syn intramolecular hydrogen-bond conformations of dipropanol phosphate obtained from molecular mechanics compared with (c) a random-coil conformation that has no hydrogen bonding. Calculated electrostatic potential maps for the corresponding 
conformers are included. Equilibrium geometries were optimized using density functional theory (B3LYP/6-31+G*, gas phase).

The presence of intramolecular hydrogen bonds is shown using computational chemistry to cause a change in the electrostatic potential (ESP) on the phosphate moiety calculated using DFT (B3LYP/6-31+G*, gas phase). In one extended state, the maximum ESP of $-574 \mathrm{~kJ} \mathrm{~mol}^{-1}$ located on one of the oxygen atoms (Figure 5c) decreases to $-533 \mathrm{~kJ} \mathrm{~mol}^{-1}$ upon $\mathrm{OH} \bullet \bullet \mathrm{O}^{-}$hydrogen bonding (anti, Figure 5a) and to a lesser degree to $-550 \mathrm{~kJ} \mathrm{~mol}^{-1}$ for the syn conformation (Figure 5b).

The conformational and electrostatic properties paint an interesting picture for recognition of these organophosphates. The favored anti structure may be too bulky to bind inside a $\pi$-stacked pair of cyanostars and it has the lowest ESP, which lowers binding energies. In the syn structure, the phosphate moiety is both more exposed and has an ESP that is $17 \mathrm{~kJ} \mathrm{~mol}^{-1}$ greater than the anti. Both factors could offer higher binding energies to help offset the energy cost $\left(16 \mathrm{~kJ} \mathrm{~mol}^{-1}\right)$ of its formation from the anti. Finally, the conformational analysis indicates that it will cost a large amount of energy $\left(>40 \mathrm{~kJ} \mathrm{~mol}^{-1}\right)$ to break even one of the $\mathrm{OH} \bullet \bullet \mathrm{O}^{-}$hydrogen bonds and unfold the dipropanol phosphate into an extended conformation. Once formed, its increased ESP (41 kJ $\mathrm{mol}^{-1}$ ) would offer stronger binding. Towards [3]pseudorotaxane formation, the $20 \mathrm{CH} \bullet \bullet \mathrm{O}^{-}$ hydrogen bonds in the 2:1 cyanostar complex with the phosphate would need to compensate for the costs of breaking the $\mathrm{OH} \bullet \bullet \mathrm{O}^{-}$contacts. One additional factor is the role of chain entropy on the formation of closed rings, ${ }^{97-99}$ which would favor the random coil form. Overall, this analysis shows that dipropanol phosphate as a more interesting recognition partner than expected, and it is still not clear if the $\mathrm{OH} \bullet \bullet \mathrm{O}^{-}$hydrogen bonds will interfere with [3]pseudorotaxane formation. 

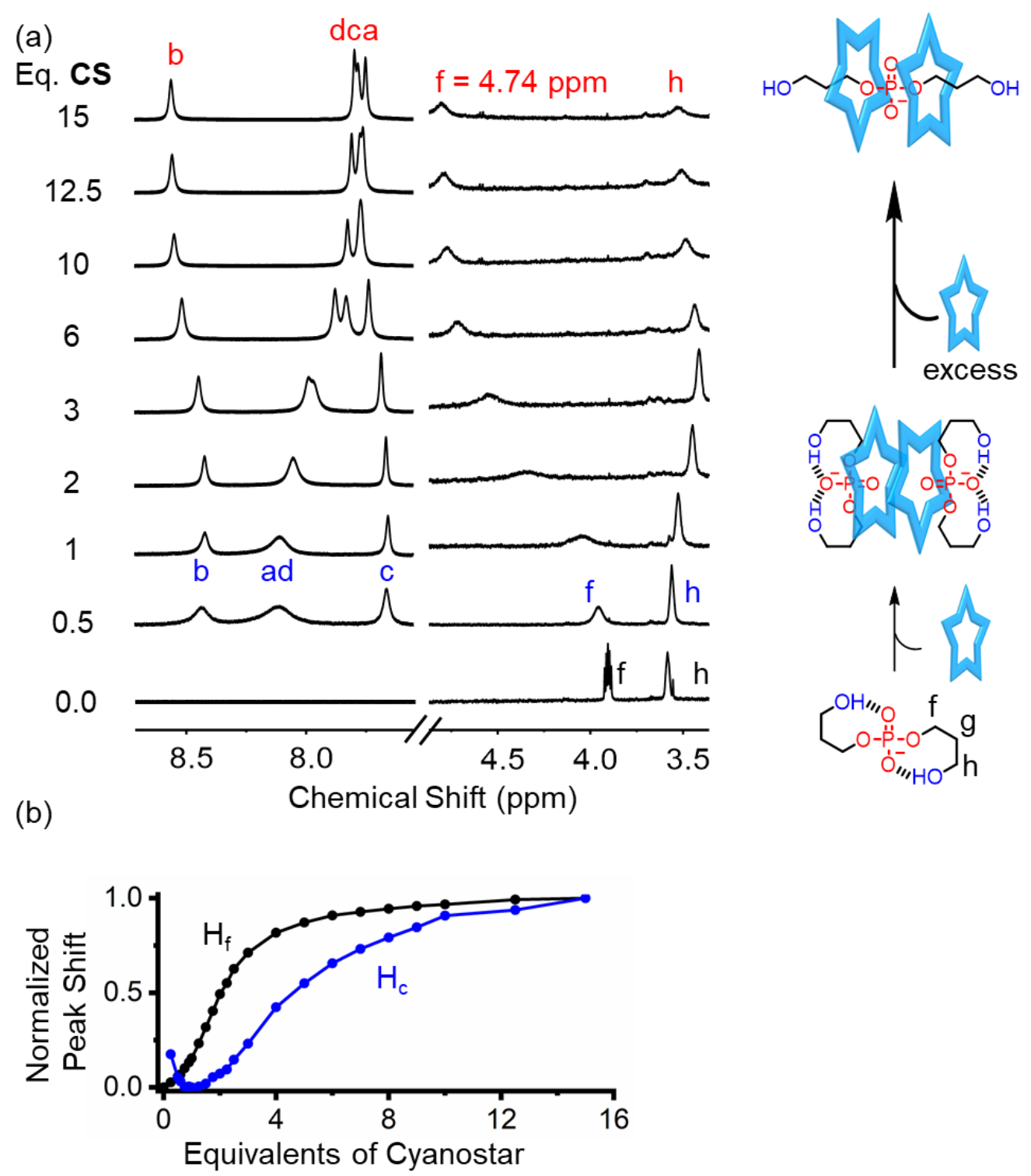

Figure 6. (a) Titration of cyanostar into dipropanol phosphate $\left(1 \mathrm{mM}, 4: 1 \mathrm{CD}_{2} \mathrm{Cl}_{2}: \mathrm{CD}_{3} \mathrm{CN}, 298\right.$ $\mathrm{K}, 600 \mathrm{MHz}$ ), and (b) normalized peak shift change of $\mathrm{H}_{\mathrm{f}}$ and $\mathrm{H}_{\mathrm{c}}$ during titration.

\section{Intramolecular Hydrogen-bonded Rings Interfere with [3]Pseudorotaxane Formation}

Clear evidence of interference from the hydroxyl groups is seen in the serpentine peak shifts (Figure 6a) in the NMR titration when cyanostar is added to dipropanol phosphate (4:1 $\mathrm{CD}_{2} \mathrm{Cl}_{2}: \mathrm{CD}_{3} \mathrm{CN}$ ). This pattern differs from the endpoint seen after 2 equivalents of cyanostar is 
added to dibutyl phosphate (Figure 3). Another difference is the change from slow exchange NMR peaks to the fast-exchange peaks seen with dipropanol phosphate (Figure 6a). The changes in chemical shift are a weighted average of various species. Thus, the serpentine binding patterns with multiple inflection points in the binding curves (Figure 6b) are consistent with the presence of at least two binding equilibria and the formation of three (or more) species in solution. ${ }^{100}$

Serpentine shifts in the peaks for the protons on the alkyl chain of the phosphate $\left(\mathrm{H}_{\mathrm{f}}, \mathrm{H}_{\mathrm{g}}\right.$, $\mathrm{H}_{\mathrm{h}}$ ) and all the aromatic protons on the cyanostar indicate that both of the self-assembling components participate in the additional equilibria. The cyanostar-based binding curves (Figure $6 b)$ show an inflection point at $\sim 1.0$ equivalents indicating an intermediate around this ratio. Based on X-ray crystallography (Figure 7, vide infra) this intermediate is expected to be a 2:2 species, which is consistent with our solution data. We investigated this intermediate further by serial dilution. At $40 \mu \mathrm{M}$, the signals closely matched the free cyanostar and uncomplexed dipropanol phosphate (Figure S15) while they saturated as the intermediate species with a clear spectrum at $5.1 \mathrm{mM}$. We were able to closely reproduce this signature in a separate experiment designed to test the idea that the 2:2 species is stabilized by bridging water molecules. Thus, we added water to a dichloromethane solution containing the [3]pseudorotaxane formed from dibutyl phosphate. The water produced new peaks (Figure S16) that show a correspondence to the ones seen with dipropanol phosphate at $5.1 \mathrm{mM}$, e.g., $\mathrm{H}_{\mathrm{c}}$ and $\mathrm{H}_{\mathrm{b}}$ grow in at the same positions as seen at $5.1 \mathrm{mM}$, while $\mathrm{H}_{\mathrm{a}}$ and $\mathrm{H}_{\mathrm{d}}$ overlap but arise in slightly different positions in this different solvent system. Nevertheless, we cannot exclude a 1:1 species. While the NMR signature does not match the situation with an anion located centrally in the binding cavity, ${ }^{101}$ a 1:1 species could also be composed of half the perched 2:2 complex seen in the crystal (Figure 7). Similar deviations in stoichiometry seen between solid state and solution structures have been observed. ${ }^{66,} 102$ 
Specifically, cyanostar formed a 2:2 and water-bridged complex in the solid state with the salicylate anion yet a 1:1 assembly in solution. ${ }^{102}$ Similarly bambusuril formed a water-bridged 1:2 bambusuril-diethyl phosphate assembly in the solid state and a 1:1 assembly in solution. ${ }^{66}$

At the end of the titration, all the peak shifts more closely match those of a [3]pseudorotaxane. Specifically, $\mathrm{H}_{\mathrm{f}}$ shifts to $4.74 \mathrm{ppm}$, which is consistent what was seen with dibutyl phosphate at $4.62 \mathrm{ppm}$ (Figure 3). The aromatic cyanostar peaks represent an average of bound and unbound macrocycles, so they are less informative. Thus, the intermediate is believed to be a complex between cyanostar and folded dipropanol phosphate that competes with formation of the [3]pseudorotaxane from the unfolded dipropanol phosphate.

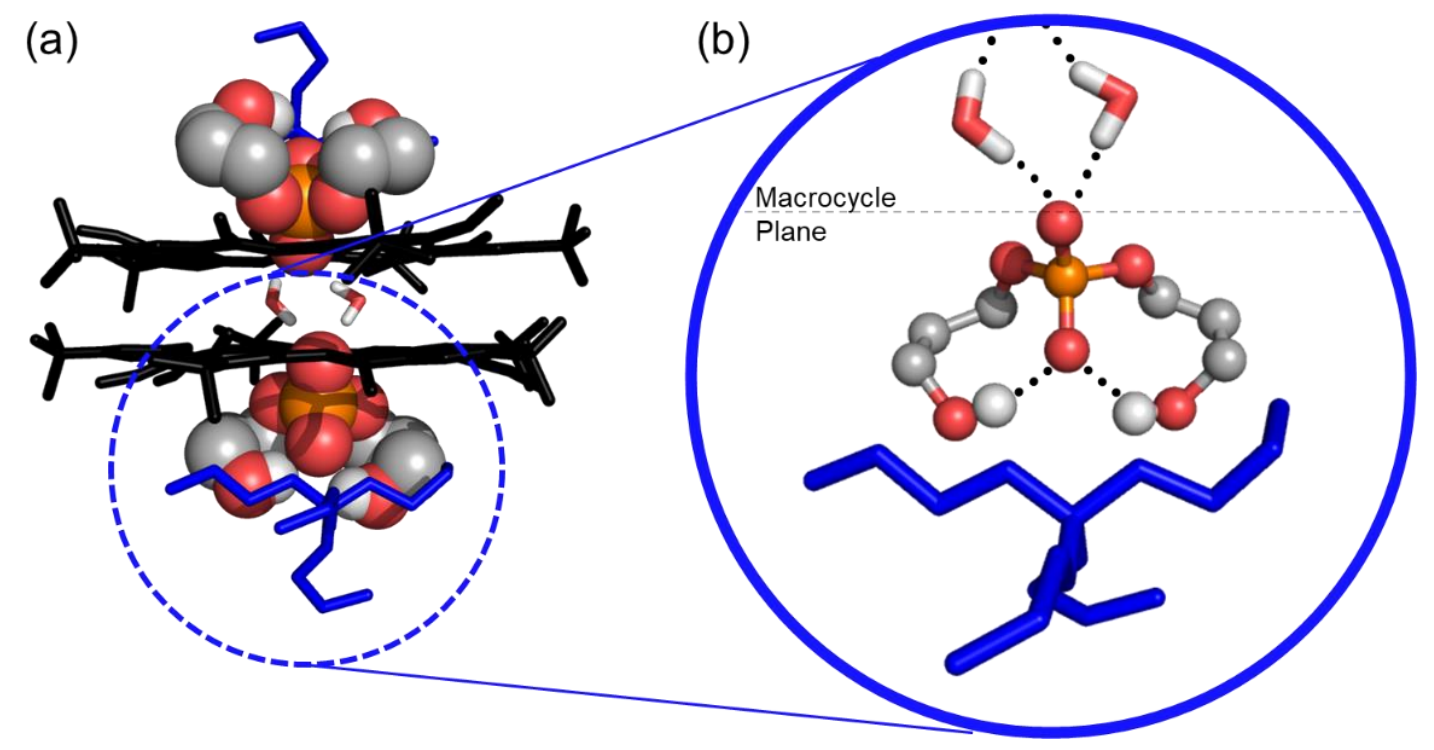

Figure 7. (a) Crystal structure showing a 2:2:2:2 assembly with cyanostar, dipropanol phosphate, tetrabutylammonium, and water respectively. (b) Syn conformation of dipropanol phosphate with O $\cdots \mathrm{O}^{-}$distances for dipropanol phosphate. Conditions: 1:1 cyanostar:dipropanol phosphate, 4:1 $\mathrm{CD}_{2} \mathrm{Cl}_{2}$ to $\mathrm{CD}_{3} \mathrm{CN}$ with slow diffusion of ethyl ether. 


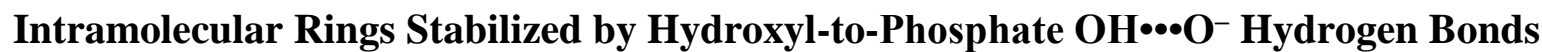

A crystal structure grown from an equimolar mixture of cyanostar and dipropanol phosphate in a dichloromethane and acetonitrile solvent mixture reveals (Figure 7) a 2:2 stoichiometry and a perched binding arrangement. The crystal structure is defined by a $\pi$-stacked dimer of macrocycles, two dipropanol phosphates, two bridging water molecules, and two $\mathrm{TBA}^{+}$counter cations. The dipropanol phosphate shows formation of two intramolecular rings residing in the syn geometry despite being less stable by $16 \mathrm{~kJ} \mathrm{~mol}^{-1}$ relative to the preferred anti geometry. When we repeated the DFT calculation to test for the role of solvent using a solvation model for dichloromethane, the energy difference between the syn and anti conformers is still sizeable at 12 $\mathrm{kJ} \mathrm{mol}^{-1}$. Thus, the syn geometry is likely formed when the cost of conformational rearrangement is repaid by more favorable cyanostar binding. This crystal structure verifies the presence of folded conformations and that medium strength $\mathrm{OH} \bullet \bullet \mathrm{O}^{-}$hydrogen bonds are important for the recognition of alcohol-substituted phosphates.

The crystal structure reveals more details about the intramolecular hydrogen bonds in the syn dipropanol phosphate. We see bifurcated hydrogen bonds with one $\mathrm{O} \cdot \bullet \bullet \mathrm{O}$ distance at $2.7 \AA$, and the other with showing disorder with $\mathrm{O} \bullet \bullet \mathrm{O}$ distances of $2.7 \AA(29 \%)$ and $2.9 \AA(71 \%)$. The average matches the computed distance of $2.8 \AA$ in the syn conformer. Both distances seen in the crystal structure are less than the sum of the oxygens' van der Waals radii of $3.04 \AA^{103}$ and consistent with Jeffrey's structural classifications ${ }^{75}$ as moderate strength hydrogen bonds.

Within the 2:2 structure, we expect electrostatic repulsions to exist between the two negatively charged phosphates. The two phosphorous atoms are $6.9 \AA$ apart with the closest approach of the oxygen atoms at $4 \AA$. Similar distances were observed with $2: 2$ complexes between cyanostar and water-bridged salicylate. ${ }^{102}$ Shorter P•••P distances, $\sim 4 \AA \AA^{26,63}$ can be supported 
inside cyanostar assemblies ${ }^{104}$ when stabilized by AEHBs ${ }^{64}$ as opposed to water bridges. ${ }^{102}$ The $\mathrm{CH} \cdot \cdots \mathrm{O}^{-}$distances between cyanostar and phosphate are $4.4 \AA$ on average consistent with weak hydrogen bonding. ${ }^{75}$ The water-to-phosphate $\mathrm{O}_{\mathrm{w}} \cdots{ }^{\circ} \mathrm{O}^{-}$distances are 2.7 and $2.9 \AA$ corresponding to moderate strength. ${ }^{75}$ Other examples of bridging waters between complexed anions, ${ }^{105}$ while rare, have been seen with bambusuril binding with diethyl phosphate ${ }^{66}$ with four bridging waters. Ion pairing is also expected to offset repulsions. To test this idea, we enhanced ion pairing by conducting the titrations between dibutyl phosphate and cyanostar in chloroform and saw the emergence of a new species in addition to the [3]pseudorotaxane (Figure S17), suggestive of competition from a perched structure. Consistently, the [3]pseudorotaxane could be reinstated upon addition of polar acetonitrile to break ion pairs (Figure S18). Overall, repulsions between phosphates will be offset by ion-pairing, the summation of many weak $\mathrm{CH}$ hydrogen bonding from inside the cyanostar, and the hydrogen bonding with bridging water molecules.

We see the anion is offset from the center of the cyanostar cavity and is $1.7 \AA$ out of the macrocycle plane. This non-ideal binding geometry helps explain the smaller changes in chemical shift observed for the perched intermediate assembly seen in solution (Figure 6). Similarly, bambusuril showed modest changes in chemical shifts in the ${ }^{1} \mathrm{H}$ NMR titration (1:1 $\mathrm{CDCl}_{3}: \mathrm{CD}_{3} \mathrm{OD}$ ), which suggests the formation of a perched assembly in solution. ${ }^{66}$

\section{Methanol Disrupts [3]Pseudorotaxane Formation}

Knowledge of the hydrogen bonding involving the terminal hydroxyl groups helps refine our understanding of phosphate recognition. One natural extension of this recognition preference is the existence of intermolecular $\mathrm{OH} \cdots \mathrm{O}^{-}$binding. We tested this idea using methanol $(\mathrm{MeOH})$ 
and expected to disrupt the [3]pseudorotaxane formation. We undertook this study using both the dialkyl and dialcohol phosphates. Consistently, the ${ }^{1} \mathrm{H}$ NMR titration with cyanostar in $20 \%$ methanol in dichloromethane (Figures S21 and S22) is different to the ones in aprotic conditions. Overall, we see small NMR shifts under fast exchange that indicate poor-to-weak binding.

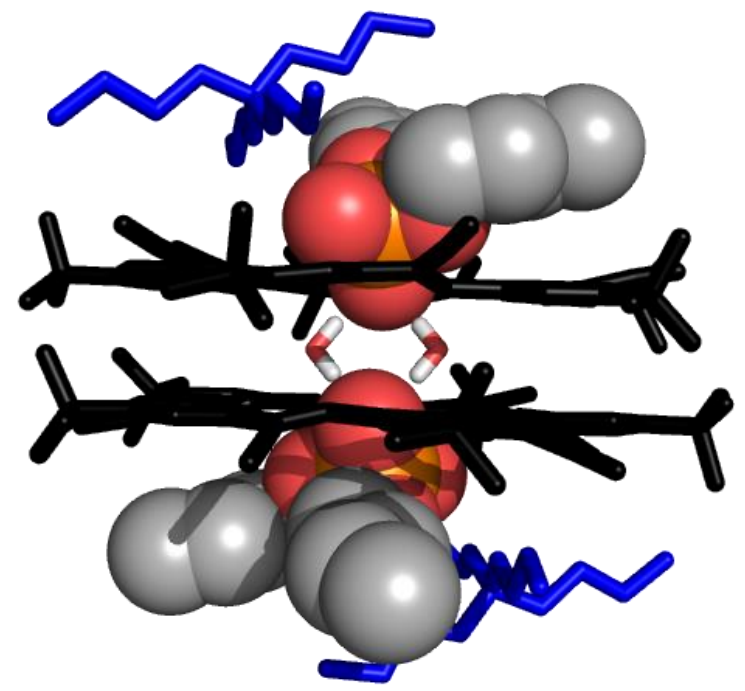

Figure 8. Crystal structure of 2:2:2:2 assembly with cyanostar, dibutyl phosphate, tetrabutylammonium, and water grown under protic conditions of 5:1 $\mathrm{CH}_{2} \mathrm{Cl}_{2}$ to $\mathrm{CD}_{3} \mathrm{OD}$ with slow diffusion of ethyl ether.

We were fortunate to obtain a crystal structure of the complex between cyanostar and dibutyl phosphate (Figure 8) that was grown under protic conditions dichloromethane:methanol). The structure showed a perched 2:2:2:2 stoichiometry between cyanostar, dibutyl phosphate, tetrabutylammonium, and water molecules that resembles the structure observed with dipropanol phosphate (Figure 7). No methanol was observed in the crystal structure. The water molecules also serve to bridge the phosphates inside the cyanostar cavity. This observation is consistent with the production of the perched structure when water was added 
to a dichloromethane solution of the [3]pseudorotaxane formed between cyanostar and dibutyl phosphate (Figure S16). These studies consistently show that $\mathrm{OH}$ hydrogen bonding regulates the recognition of organophosphates.

\section{Recovering [3]Pseudorotaxanes by Synthetic Control over the Entropy of Ring Formation}

Knowledge of how $\mathrm{OH} \bullet \bullet \mathrm{O}^{-}$hydrogen bonding disrupts recognition of organophosphates, we investigated a strategy to recover [3]pseudorotaxane formation in the presence of hydroxyl groups. We drew inspiration from the entropic ${ }^{60}$ contributions to ring formation. ${ }^{106}$ The entropic penalties of forming an 8-membered ring with the propanol substituent are higher relative to an 11-membered ring that forms with hexanol. ${ }^{107,108}$ Lengthening the alkyl linkers of the alcohol substituents should disfavor the formation of folded conformations and their intramolecular hydrogen bonds to recover strong binding and high-fidelity [3]pseudorotaxane formation.

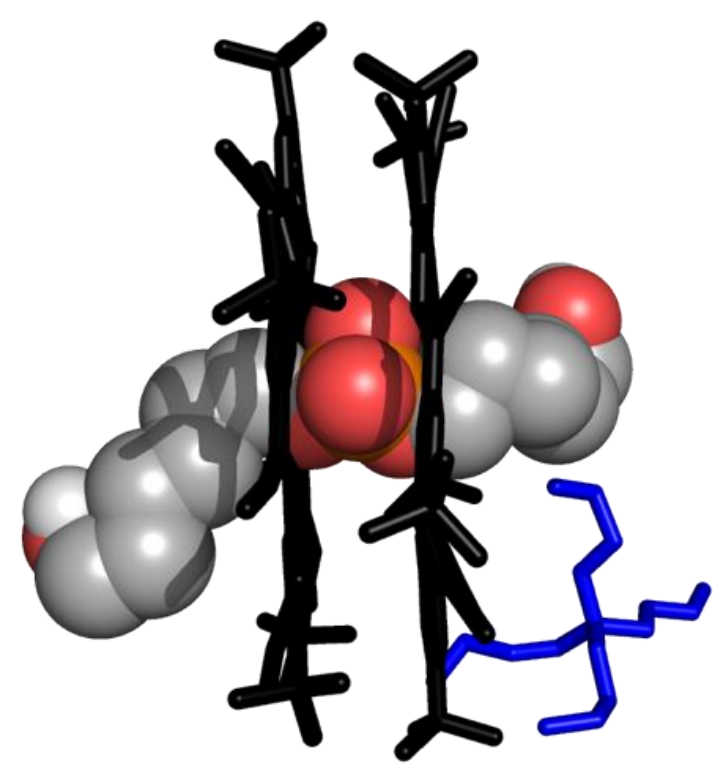

Figure 9. Crystal structure of [3]pseudorotaxane between cyanostar and dihexanol phosphate grown in $4: 1 \mathrm{CD}_{2} \mathrm{Cl}_{2}$ to $\mathrm{CD}_{3} \mathrm{CN}$ by vapor diffusion of hexane. 
To test the entropic hypothesis, dihexanol and didecanol phosphate threads were selected to probe the length threshold needed to shut down folding. Both show the same formation of intramolecular hydrogen bonds in the gas phase (Figures S2 and S3). Exactly as was seen with dipropanol phosphate, all 500 conformations for each thread within $40 \mathrm{~kJ} \mathrm{~mol}^{-1}$ were folded with $\mathrm{OH} \bullet \bullet \mathrm{O}^{-}$hydrogen bonds. This outcome is expected when considering that the calculations do not include entropy and thus more closely resemble the enthalpic stability of these conformations.

The large ring systems formed with dihexanol and didecanol do not persist in solutions when subject to free energy. Consistent with the behavior of dibutyl phosphate, the ${ }^{31} \mathrm{P}-{ }^{1} \mathrm{H}_{\mathrm{f}}$ coupling constants of 6.4 and $6.5 \mathrm{~Hz}$ in aprotic solvent conditions indicate that dihexanol and didecanol phosphate, respectively, both exist in extended random-coil conformations (Figure S26). Gratifyingly, longer linkers recovered high-fidelity [3]pseudorotaxane formation in the solid state (Figure 9). The terminal hydroxyls do not fold back to point towards the phosphate in this structure.

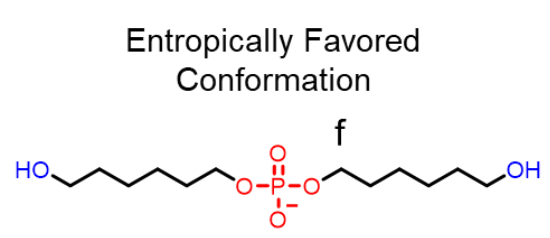

(a)

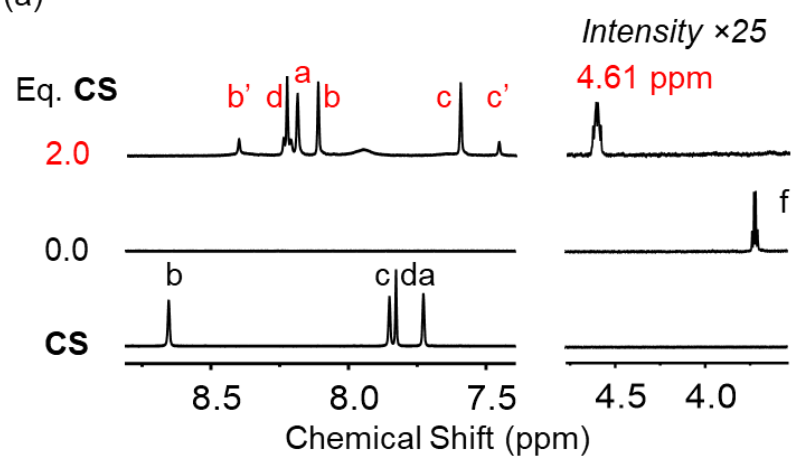

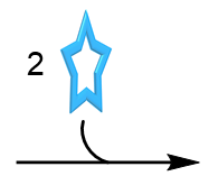

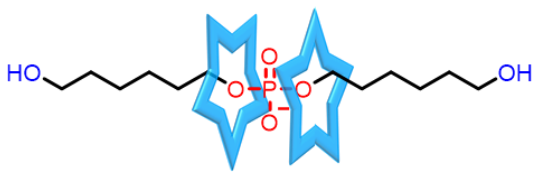

(b)

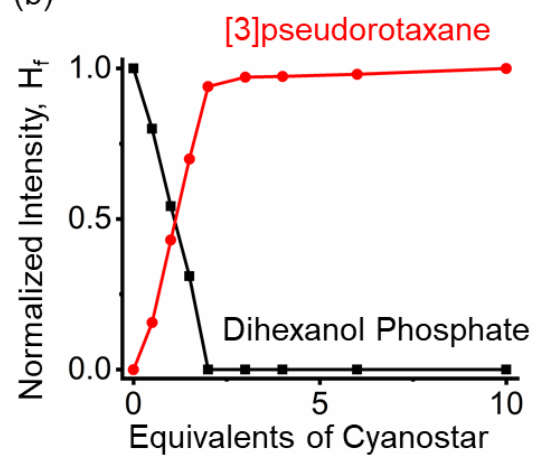

Figure 10. (a) Titration of cyanostar into dihexanol phosphate $\left(1 \mathrm{mM}, 4: 1 \mathrm{CD}_{2} \mathrm{Cl}_{2}: \mathrm{CD}_{3} \mathrm{CN}, 298\right.$ K, $600 \mathrm{MHz}$ ). (b) Normalized peak intensities. 
The ${ }^{1} \mathrm{H}$ NMR titration studies of cyanostar added to dihexanol phosphate $(4: 1$ $\mathrm{CD}_{2} \mathrm{Cl}_{2}: \mathrm{CD}_{3} \mathrm{CN}$, Figure $10 \mathrm{a}$ ) showed the recovery of a tight-binding [3]pseudorotaxane (Figure 10b). The cyanostar's diastereomer peaks were also present upon complexation with dihexanol phosphate (Figure 10a) indicative of $\pi$ stacking. The ${ }^{31} \mathrm{P}$ NMR spectra also show diastereomer peaks with consistent meso-chiral peak intensities (Figure S14). To illustrate the generality of the strategy to increase the alkyl chains to recover [3]pseudorotaxane formation, didecanol phosphate was also examined. Didecanol phosphate formed meso and chiral [3]pseudorotaxanes with cyanostar in solution (Figure 11), and the threaded architecture was confirmed by a ${ }^{1} \mathrm{H}-{ }^{1} \mathrm{H}$ ROESY (Figure S11). The meso and chiral [3]pseudorotaxanes formed with didecanol phosphate are also consistent with the dibutyl and dihexanol phosphate [3]pseudorotaxanes (Figure 11). Overall, these studies show that we can alter the design of phosphate's organic substituent to control the supramolecular assemblies that form.

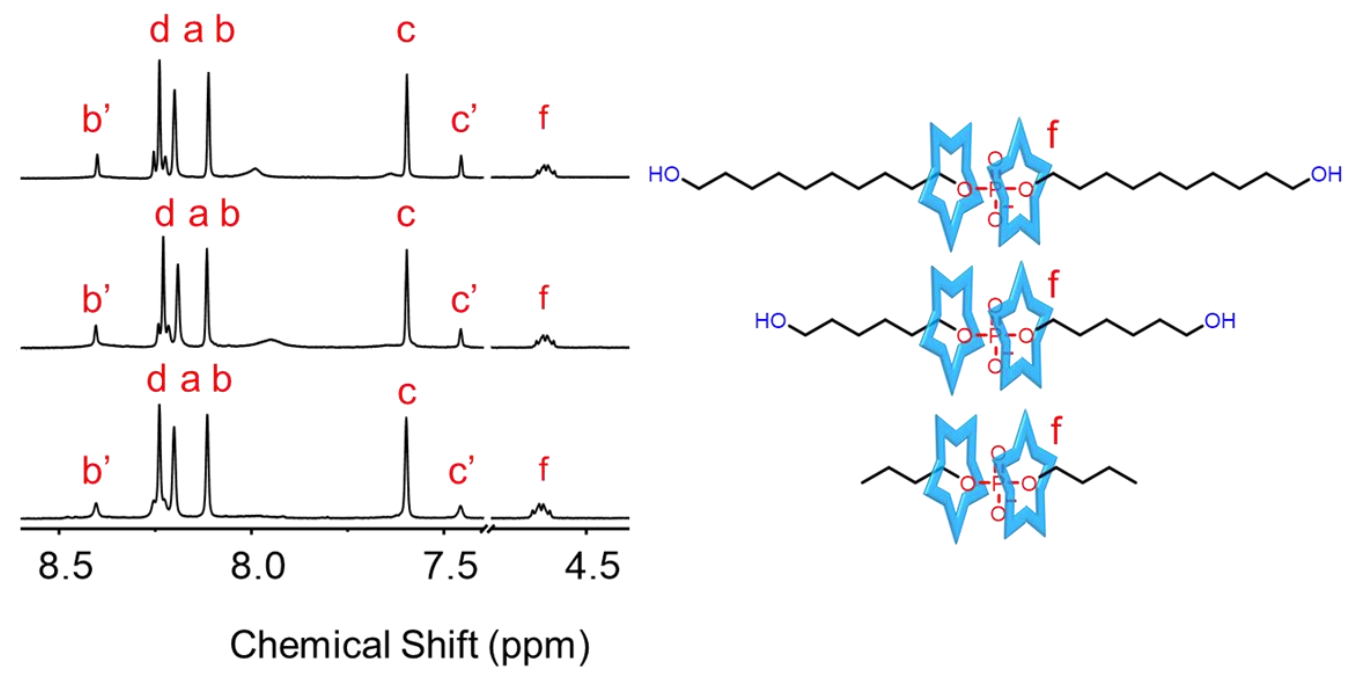

Figure 11. Coincident NMR signatures of [3]pseudorotaxanes formed in a 2:1 mixture of cyanostar $(2 \mathrm{mM})$ and the dibutyl, dihexanol, and didecanol phosphates $\left(4: 1 v / v \mathrm{CD}_{2} \mathrm{Cl}_{2}: \mathrm{CD}_{3} \mathrm{CN}\right.$, $298 \mathrm{~K}, 600 \mathrm{MHz})$. 


\section{Implications of $\mathrm{OH}^{\bullet \bullet \mathrm{O}^{-}} \mathrm{Hydrogen}$ Bonding on Organophosphate Recognition}

Formation of intramolecular $\mathrm{OH} \bullet \bullet \mathrm{O}^{-}$bonds to organophosphate molecules has the potential to inform studies, observations, and uses of phosphate recognition across chemistry and biology. The $\mathrm{OH} \bullet \bullet \mathrm{O}^{-}$contact is sufficiently strong ${ }^{82}$ that it can be used as a reliable and therefore programmable ${ }^{109}$ contact for phosphate binding. The caveat being that water and alcohol based solvents ${ }^{110}$ are best avoided. Alternatively, solvent-excluded binding pockets based on capsular foldamers offer a novel strategy to circumvent this problem, ${ }^{111,112}$ which is consistent with observations of these hydrogen bonding contacts in biomolecular recognition events even in aqueous solutions. ${ }^{86}$ In addition, while phenol can be deprotonated $\left(\mathrm{p} K_{\mathrm{a}}=18\right),{ }^{113}$ alkyl alcohols have higher $\mathrm{p} K_{\mathrm{a}}$ values $(29-32.2),{ }^{114}$ which might facilitate use of alkyl alcohols in organophosphate recognition. It is also clear that the formation of $\mathrm{OH} \bullet \bullet \mathrm{O}^{-}$contacts could stabilize foldamers $^{22,115}$ and now rotaxanes ${ }^{116}$ when this interaction is shut down. Our findings also strongly support the role of $\mathrm{OH} \bullet \bullet \mathrm{O}^{-}$hydrogen bonding inferred in enantioselective catalysis using chiral phosphates. $^{87}$

\section{Conclusion}

We discovered that the recognition of organophosphates depends on competitive $\mathrm{OH} \bullet \bullet \mathrm{O}^{-}$ hydrogen bonding as well as the conformations of the organic substituent, and that we can control these factors to direct formation of cyanostar-based [3]pseudorotaxanes. When using alkyl substituents, [3]pseudorotaxanes are formed with 2:1 cyanostar-phosphate stoichiometries unless the reaction is undertaken in protic solvent mixtures or where ion pairing is expressed. When terminal hydroxyls are introduced using dipropanol phosphate, favorable $\mathrm{OH} \bullet \bullet \mathrm{O}^{-}$hydrogen bonding drives formation of eight-membered rings. These conformations lead to complexes with 
the folded dipropanol phosphate merely perched on the cyanostar cavity and competitively interfering with threaded complexes. [3]Pseudorotaxanes could be recovered, even in the presence of the enthalpically favored $\mathrm{OH} \bullet \bullet \mathrm{O}^{-}$hydrogen bonds, simply by lengthening the intervening chain to increase the entropic penalties associated with ring formation. Dihexanol phosphate, with an extra three methylene groups, was sufficient to ensure high-fidelity formation of [3]pseudorotaxanes in the solid state and in solution. This is one of a few examples using entropy in non-covalent synthesis. ${ }^{61}$ This study opens up the opportunity to use alcohol-substituted threads in the formation of pseudorotaxanes and lays a foundation for investigating the use of organic substituents to regulate the recognition of organophosphates.

\section{Experimental Section}

\section{General Methods}

All reagents were obtained from commercial suppliers and used as received unless otherwise noted. Succinic anhydride ( $\geq 99 \%$, Sigma-Aldrich), 1,3-propanediol (99\%, Alfa Aesar), 1,6-hexanediol (> 97\%, TCI), 1,10-decanediol (> 97\%, TCI), 2-cyanoethyl diisopropylchlorophosphoramidite (95\%, Alfa Aesar), 4,4'-dimethoxytriphenylmethyl chloride (DMTrCl or DMTCl, $\geq 97.0 \%$, Sigma-Aldrich), N,N-diisopropylethylamine (DIPEA, 99\%, Alfa Aesar), 4-(dimethylamino)pyridine $\quad$ (DMAP, $\quad 99 \%, \quad$ Sigma-Aldrich), $\quad N_{,} N^{\prime}-$ dicyclohexylcarbodiimide, (99\%, DCC, Alfa Aesar), aminopolystyrene resin (1.4 $\mathrm{mmol} \mathrm{g}^{-1}$, Novabiochem), trichloroacetic acid ( $\geq 99 \%$, Sigma-Aldrich), tetrabutylammonium hydroxide (1 $\mathrm{M}$ in methanol, Sigma-Aldrich), 1,4-dioxane ( $\geq 99.5 \%$, Alfa Aesar), ammonium hydroxide ( $\geq 28 \%$ $\mathrm{NH}_{3}$ in $\mathrm{H}_{2} \mathrm{O}$, VWR), iodine ( >99\%, Prolabo), piperidine (99\%, Alfa Aesar), triethylamine (97\%, Acros Organics), were used as purchased. Anhydrous dichloromethane, pyridine and acetonitrile 
were purchased from Aldrich. Anhydrous THF was obtained using a dry solvent station GT S100. Dibutyl phosphate was purchased from Sigma-Aldrich. The cyanostar macrocycle was synthesized from 5-tert-butylisothalic acid using reported methods. ${ }^{24}$

Thin-layer chromatography (TLC) was performed on pre-coated silica-gel plates $(0.25 \mathrm{~mm}$ thick, Silicycle), and the plates were observed under long (248 nm) and short wavelength UV light. Column chromatography was performed on silica gel (160-200 mesh, Sorbtech). NMR Spectra were recorded on Varian Inova (400 MHz, $500 \mathrm{MHz}$, and $600 \mathrm{MHz}$ ), Varian VXR (400 MHz) at room temperature $(298 \mathrm{~K})$, and Bruker Advance $(400 \mathrm{MHz})$ spectrometer. Chemical shifts were referenced using residual solvent peaks or $85 \%$ phosphoric acid. Spectroscopic grade solvents $\left(\mathrm{CH}_{2} \mathrm{Cl}_{2}, \quad \mathrm{CH}_{3} \mathrm{CN}, \quad \mathrm{CH}_{3} \mathrm{OH}, \mathrm{CHCl}_{3}\right.$, Omnisolve) were used as received to prepare tetrabutylammonium salts and titration stock solutions. Deuterated solvents $\left(\mathrm{CD}_{2} \mathrm{Cl}_{2}, \mathrm{CD}_{3} \mathrm{CN}\right.$, $\mathrm{CD}_{3} \mathrm{OD}, \mathrm{CDCl}_{3}$, Sigma Aldrich and Cambridge Isotope Laboratories) were used as received. High resolution electrospray ionization mass spectrometry (ESI-MS) were performed on a Thermo Electron Corporation MAT 95XP-Trap mass spectrometer and on a QStar Elite mass spectrometer (Applied Biosystems SCIEX, Concord, ON, Canada).

\section{General synthesis of phosphoramidite monomers}

The disubstituted phosphates examined in this work were obtained by solid-phase phosphoramidite chemistry. For that purpose, phosphoramidite reagents and modified resins were first prepared. The phosphoramidite monomers employed in this work were synthesized following the protocol depicted in Scheme 1. This protocol was previously utilized for the synthesis of 6-(4,4'dimethoxytriphenylmethyloxy)propyl 2-cyanoethyl $N, N$-diisopropylphosphoramidite and the monoprotected intermediate 3-(4,4'-dimethoxytriphenylmethyloxy)propan-1-ol. ${ }^{17}$ 


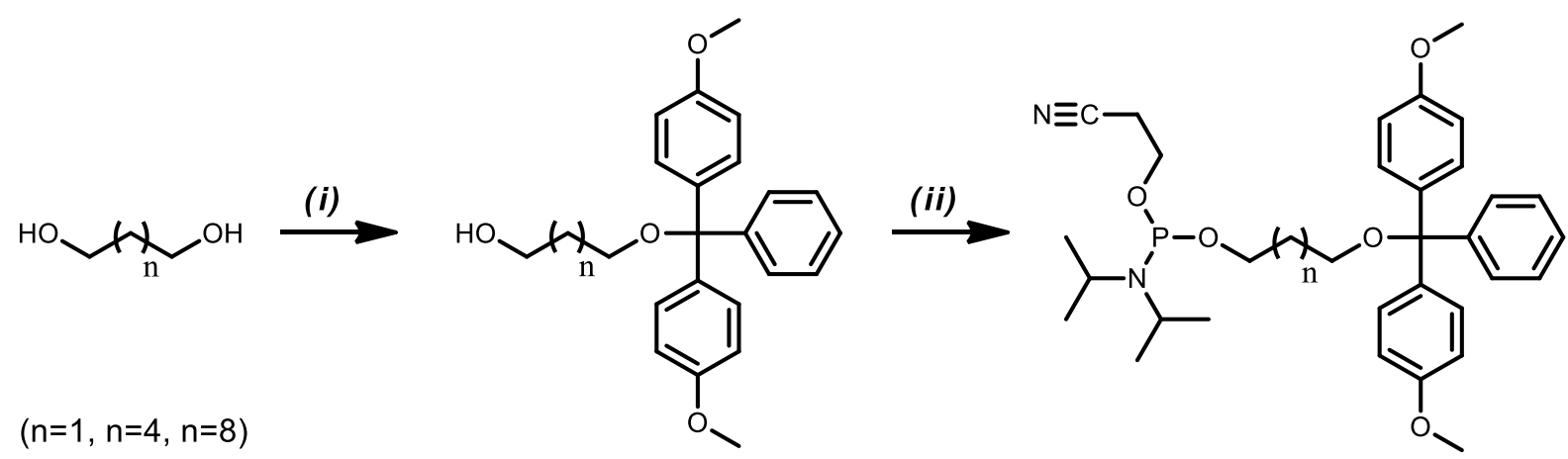

Scheme 1. Synthesis of the intermediates 4,4'-dimethoxytrityl-diol and the phosphoramidite monomers. (i) DMTrCl, DIPEA, $\mathrm{CH}_{2} \mathrm{Cl}_{2}$; (ii) (iPr) ${ }_{2} \mathrm{NP}(\mathrm{Cl}) \mathrm{OCH}_{2} \mathrm{CH}_{2} \mathrm{CN}$, DIPEA, $\mathrm{CH}_{2} \mathrm{Cl}_{2}$.

Synthesis of 6-(4,4'-dimethoxytriphenylmethyloxy)hexan-1-ol. 1,6-Hexandiol (1.5 g, 12.6 mmol) was co-evaporated with $8 \mathrm{~mL}$ of anhydrous pyridine. Afterwards, $8 \mathrm{~mL}$ of pyridine and $15 \mathrm{~mL}$ of anhydrous THF were introduced and the diol was reacted with 4,4'-dimethoxytrityl chloride (DMTCl) (4.3 g, $12.6 \mathrm{mmol})$. The DMTCl was added in four equal portions at a rate of one portion every hour. After the four additions, the mixture was stirred at room temperature for two hours. The reaction was stopped with the addition of $8 \mathrm{~mL}$ of methanol and the mixture was evaporated to dryness. The residue was dissolved in ethyl acetate $(50 \mathrm{~mL})$ and washed with $5 \%$ sodium bicarbonate ice-cold solution. The aqueous layer was extracted with $50 \mathrm{~mL}$ of ethyl acetate. The combined organic layers were washed with water and brine, dried with anhydrous $\mathrm{Na}_{2} \mathrm{SO} 4$ and evaporated. The resulting product was chromatographed on silica gel (30\% ethyl acetate in cyclohexane with a $1 \%$ triethylamine) yielding: $3.09 \quad \mathrm{~g}$ of $6-\left(4,4^{\prime}-\right.$ dimethoxytriphenylmethyloxy)hexan-1-ol (58\%) as a colorless oil. ${ }^{1} \mathrm{H} \mathrm{NMR}\left(400 \mathrm{MHz}, \mathrm{CDCl}_{3}\right) \delta$ $7.46-7.42(\mathrm{~m}, 2 \mathrm{H}), 7.37-7.24\left(\mathrm{~m}, 6{ }^{1} \mathrm{H}\right.$ peak partially overlapping with residual solvent peak), $7.22-7.18(\mathrm{~m}, 1 \mathrm{H}), 6.85-6.80(\mathrm{~m}, 4 \mathrm{H}), 3.79(\mathrm{~s}, 6 \mathrm{H}), 3.65-3.59(\mathrm{~m}, 2 \mathrm{H}), 3.05(\mathrm{t}, J=6.6 \mathrm{~Hz}$, 2H), $1.67-1.22(\mathrm{~m}, 8 \mathrm{H}) .{ }^{13} \mathrm{C}\left\{{ }^{1} \mathrm{H}\right\} \mathrm{NMR}\left(100 \mathrm{MHz}, \mathrm{CDCl}_{3}\right) \delta 158.4,145.5,136.8,130.1,128.3$, 
127.8, 126.7, 113.1, 85.8, 63.4, 63.1, 55.3, 32.9, 30.2, 26.3, 25.8. HRMS (ESI) m/z: $[\mathrm{M}+\mathrm{Na}]^{+}$ Calcd for $\mathrm{C}_{27} \mathrm{H}_{32} \mathrm{O}_{4} \mathrm{Na}^{+}$443.2193; Found 443.2183.

Synthesis of 10-(4,4'-dimethoxytriphenylmethyloxy)decan-1-ol. Following the procedure above 1,10-decandiol (2.34 g, $13.4 \mathrm{mmol})$ was reacted with 4,4'-dimethoxytrityl chloride (DMTCl) (4.56 g, $13.4 \mathrm{mmol})$. The resulting product was chromatographed on silica gel (30\% ethyl acetate in cyclohexane with a $1 \%$ triethylamine) yielding 3.5 g of 10-(4,4'dimethoxytriphenylmethyloxy)decan-1-ol (55\%) as a colorless oil. ${ }^{1} \mathrm{H}$ NMR (400 MHz, $\left.\mathrm{CDCl}_{3}\right) \delta$ ${ }^{1} \mathrm{H}$ NMR $\left(400 \mathrm{MHz}, \mathrm{CDCl}_{3}\right) \delta 7.46-7.42(\mathrm{~m}, 2 \mathrm{H}), 7.35-7.25\left(\mathrm{~m}\right.$, six ${ }^{1} \mathrm{H}$ peak partially overlapping with residual solvent peak), $7.22-7.14(\mathrm{~m}, 2 \mathrm{H}), 6.83$ (ddd, $J=9.0,4.9,2.2 \mathrm{~Hz}, 4 \mathrm{H}$ ), $3.79(\mathrm{t}, J=3.9 \mathrm{~Hz}, 6 \mathrm{H}), 3.64(\mathrm{td}, J=6.6,2.6 \mathrm{~Hz}, 2 \mathrm{H}), 3.03(\mathrm{td}, J=6.6,1.7 \mathrm{~Hz}, 2 \mathrm{H}), 1.65-1.50$ (m, 4H) $1.40-1.20$ (m, twelve ${ }^{1} \mathrm{H}$ peak partially overlapping with residual water). ${ }^{13} \mathrm{C}\left\{{ }^{1} \mathrm{H}\right\}$ NMR $\left(100 \mathrm{MHz}, \mathrm{CDCl}_{3}\right) \delta 158.4,145.6,136.9,130.2,128.3,127.8,126.6,113.1,85.7,63.6,63.2,55.3$, 32.94, 32.92, 30.2, 29.7, 29.6, 29.5, 26.4, 25.9. HRMS (ESI) m/z: $[\mathrm{M}+\mathrm{Na}]^{+}$Cald for $\mathrm{C}_{31} \mathrm{H}_{40} \mathrm{O}_{4} \mathrm{Na}^{+}$ 499.2819; Found 499.2830.

Synthesis of 6-(4,4'-dimethoxytriphenylmethyloxy)hexyl 2-cyanoethyl $\quad N, N$ diisopropylphosphoramidite. 6-(4,4'-Dimethoxytriphenylmethyloxy)hexan-1-ol (2.0 g, 4.75 mmol) was coevaporated with $8 \mathrm{~mL}$ of anhydrous dichloromethane and dried under vacuum over 30 min then $0.1 \mathrm{~g}$ of molecular sieves $(3 \AA$ ) were added. $12 \mathrm{~mL}$ of anhydrous dichloromethane and DIPEA (4.1 ml, $23.7 \mathrm{mmol}$ ) was added successively under argon and the system was cooled with an ice-water bath. O-2-cyanoethyl-N,N-diisopropylchlorophosphoramidite (1.2 g, $5.0 \mathrm{mmol})$ was added dropwise with continuous stirring. The reaction flask was then allowed to warm to room 
temperature and stirred for $1 \mathrm{hr}$. The mixture was evaporated to dryness and dissolved in ethyl acetate then chromatographed directly on silica gel using hexane / ethyl acetate (3:2) $+1 \%$ trimethylamine as eluent yielding $2.26 \mathrm{~g}$ of phosphoramidite (79\%) as a foam. ${ }^{1} \mathrm{H} \mathrm{NMR}(400 \mathrm{MHz}$, $\left.\mathrm{CDCl}_{3}\right) \delta 7.48-7.40(\mathrm{~m}, 2 \mathrm{H}), 7.38-7.24(\mathrm{~m}, 6 \mathrm{H}), 7.23-7.17(\mathrm{~m}, 1 \mathrm{H}), 6.87-6.78(\mathrm{~m}, 4 \mathrm{H}), 3.89$ $-3.75(\mathrm{~m}, 8 \mathrm{H}), 3.70-3.53(\mathrm{~m}, 4 \mathrm{H}), 3.05(\mathrm{t}, J=6.6 \mathrm{~Hz}, 2 \mathrm{H}), 2.62(\mathrm{t}, J=6.5 \mathrm{~Hz}, 2 \mathrm{H}), 1.67-1.57$ (m, 4H), $1.44-1.30(\mathrm{~m}, 4 \mathrm{H}), 1.23-1.14(\mathrm{~m}, 12 \mathrm{H}) .{ }^{13} \mathrm{C}\left\{{ }^{1} \mathrm{H}\right\}$ NMR $\left(100 \mathrm{MHz}, \mathrm{CDCl}_{3}\right) \delta 158.4$, $145.5,136.8,130.1,128.3,127.8,126.6,117.8,113.0,85.7,63.7(\mathrm{~d}, J=17.1 \mathrm{~Hz}), 63.5,58.4(\mathrm{~d}, J$ $=19.0 \mathrm{~Hz}), 55.3,43.1(\mathrm{~d}, J=12.3 \mathrm{~Hz}), 31.3(\mathrm{~d}, J=7.2 \mathrm{~Hz}), 30.2,26.2,26.0,24.9-24.5(\mathrm{~m}), 20.4$ $(\mathrm{d}, J=6.8 \mathrm{~Hz}) .{ }^{31} \mathrm{P}$ NMR $\left(162 \mathrm{Mhz}, \mathrm{CDCl}_{3}\right) \delta$ 147.20. HRMS (ESI) m/z: $[\mathrm{M}+\mathrm{Na}]^{+}$Calcd for $\mathrm{C}_{36} \mathrm{H}_{49} \mathrm{~N}_{2} \mathrm{O}_{5} \mathrm{PNa}^{+}$643.3271; Found 643.3258.

Synthesis of 10-(4,4'-dimethoxytriphenylmethyloxy)decyl 2-cyanoethyl N,Ndiisopropylphosphoramidite. 10-(4,4'-Dimethoxytriphenylmethyloxy)decan-1-ol (0.9 g, 1.88 mmol) was reacted with O-2-cyanoethyl-N,N-diisopropyl-chlorophosphoramidite (0.49 g, 2.0 $\mathrm{mmol})$ and DIPEA $(1.75 \mathrm{ml}, 10 \mathrm{mmol})$ as described above. The resulting product was purified by chromatography on silica gel (hexane / ethyl acetate (7:3) $+1 \%$ triethylamine) yielding $1.2 \mathrm{~g}$ of phosphoramidite (94\%) as a colorless liquid foam. ${ }^{1} \mathrm{H}$ NMR (400 MHz, $\left.\mathrm{CDCl}_{3}\right) \delta 7.47-7.43(\mathrm{~m}$, 2H), $7.37-7.26(\mathrm{~m}, 6 \mathrm{H}), 7.23-7.18(\mathrm{~m}, 1 \mathrm{H}), 6.85-7.81(\mathrm{~m}, 4 \mathrm{H}), 3.91-3.76(\mathrm{~m}, 8 \mathrm{H}), 3.72-$ $3.54(\mathrm{~m}, 4 \mathrm{H}), 3.04(\mathrm{t}, J=6.6 \mathrm{~Hz}, 2 \mathrm{H}), 2.63(\mathrm{t}, J=6.6 \mathrm{~Hz}, 2 \mathrm{H}), 1.63(\mathrm{dq}, J=14.3,7.4,6.7 \mathrm{~Hz}, 4 \mathrm{H})$, $1.40-1.23(\mathrm{~m}, 12 \mathrm{H}), 1.20(\mathrm{dd}, J=6.8,4.6 \mathrm{~Hz}, 12 \mathrm{H}) .{ }^{13} \mathrm{C}\left\{{ }^{1} \mathrm{H}\right\} \mathrm{NMR}\left(100 \mathrm{MHz}, \mathrm{CDCl}_{3}\right) \delta 158.4$, 145.6, 136.9, 130.1, 128.3, 127.8, 126.6, 117.8, 113.0, 85.7, $63.8(\mathrm{~d}, J=17.2 \mathrm{~Hz}), 63.6,58.4(\mathrm{~d}, J$ $=18.9 \mathrm{~Hz}), 55.3\left(\mathrm{two}{ }^{13} \mathrm{C}\right.$ peaks overlap), $43.1(\mathrm{~d}, J=12.3 \mathrm{~Hz}), 31.3(\mathrm{~d}, J=7.2 \mathrm{~Hz}), 30.2,29.6$, 
29.4, 26.4, 26.0, $24.7(\mathrm{dd}, J=10.3,7.2 \mathrm{~Hz}), 20.4(\mathrm{~d}, J=6.8 \mathrm{~Hz}) .{ }^{31} \mathrm{P}$ NMR $\left(162 \mathrm{MHz}, \mathrm{CDCl}_{3}\right) \delta$ 147.20. HRMS (ESI) m/z: [M+Na] ${ }^{+}$Calcd for $\mathrm{C}_{40} \mathrm{H}_{57} \mathrm{~N}_{2} \mathrm{O}_{5} \mathrm{PNa}^{+}$699.3897; Found 699.3883.

\section{Preparation of modified resins}

Functional resins were synthesized following the protocol shown in Scheme 2. It involves first the synthesis of an intermediate succinate that is then coupled to a commercial aminopolystyrene resin. This synthesis was already reported for $\mathrm{n}=1 .^{17}$

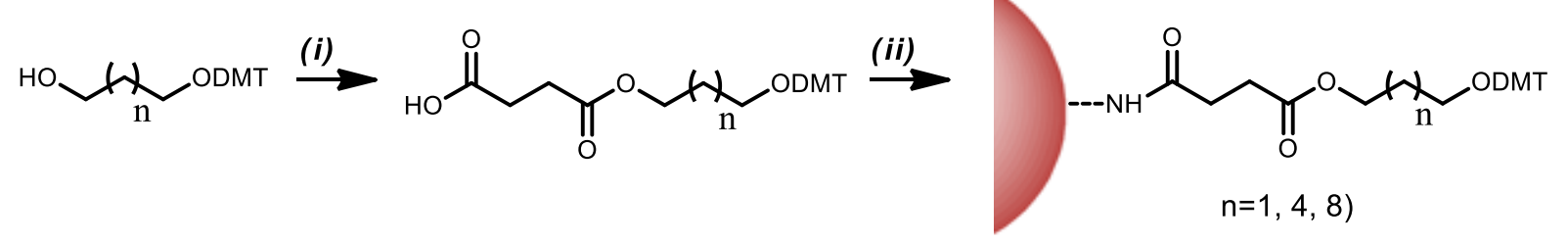

Scheme 2. Synthesis of intermediate succinates and resin modification (red bead). (i) Succinic anhydride, DMAP, pyridine; (ii) DCC, $\mathrm{CH}_{2} \mathrm{Cl}_{2}$

Synthesis of succinate intermediates. In a $25-\mathrm{mL}$ round bottom flask, a monoprotected diol (either 6-(DMT)hexan-1-ol or 10-(DMT)decan-1-ol) (1 mmol) was co-evaporated with $4 \mathrm{~mL}$ of pyridine, dried under vacuum for 30 min and then reacted with 1.5 equivalents of succinic anhydride and 1.5 equivalents of DMAP in $4 \mathrm{~mL}$ of anhydrous pyridine at $35^{\circ} \mathrm{C}$ for $5 \mathrm{~h}$. The reactions were quenched with methanol and the solvent concentrated. The resulting oils were diluted with ethyl acetate $(20 \mathrm{~mL})$ and washed with water, $0.1 \mathrm{M}$ sodium phosphate $(\mathrm{pH} 5.0)$, and again water. The 
organic phases were dried with $\mathrm{MgSO}_{4}$ and the solvent evaporated to dryness to give colorless oils in quantitative yields which were used without any further purification.

Resin modification. The appropriate succinate $(0.73 \mathrm{mmol})$ was reacted with $0.4 \mathrm{~g}$ of aminopolystyrene resin $\left(1.4 \mathrm{mmol} \mathrm{g} \mathrm{g}^{-1}\right), 0.26 \mathrm{mmol}$ of DMAP and $2.26 \mathrm{mmol}$ of DCC in $5 \mathrm{~mL}$ of anhydrous dichloromethane following a previously reported procedure. ${ }^{17}$ The unreacted amino groups were capped with acetic anhydride in pyridine $(1: 5 \mathrm{v} / \mathrm{v})$. The loading of the support was determined by the removal of the DMT group of an aliquot and analyzing its absorbance at 504 $\mathrm{nm}$ to find a loading of about $0.8 \mathrm{mmol} \mathrm{\textrm {g } ^ { - 1 }}$.

\section{General Synthesis of the disubstituted phosphates.}

The disubstituted phosphates were obtained by phosphoramidite coupling, carried out under vacuum-argon in rigorously dry conditions using a home-made peptide synthesis reaction vessel as shown in Scheme 3. The general procedure is the following one: 1 molar equivalent of polystyrene support $\left(0.8 \mathrm{mmol} \mathrm{g}^{-1}\right)$ was introduced in the reaction vessel, treated with a $3 \%$ trichloroacetic acid solution in dichloromethane and washed with a solution of $2 \%$ pyridine in acetonitrile and again with pure acetonitrile. After a fast swelling in dichloromethane, the appropriate phosphoramidite (1.5 equiv.) dissolved in anhydrous acetonitrile $(0.1 \mathrm{M})$ and tetrazole (4 eq, $0.45 \mathrm{M}$ solution in acetonitrile) were added under argon atmosphere. The reactor was shaken at room temperature for 15 minutes. Afterwards, the solution was removed and the polystyrene support was washed with acetonitrile and the resulting phosphite-triester was oxidized during 2 minutes to phosphate-triester with a $0.1 \mathrm{M}$ iodine solution $\left(\mathrm{I}_{2}\right.$ in water/pyridine/THF 2/20/80). The excess of iodine was removed by acetonitrile and dichloromethane washes. Finally, deprotection 
of the cyanoethyl phosphate protecting group was performed using a $10 \%$ piperidine solution in acetonitrile (5 $\mathrm{min}$ ), the terminal DMT-protecting group was deprotected using the $3 \%$ trichloroacetic acid solution and the disubstituted phosphates were cleaved from the resins using $30 \%$ aqueous ammonia solution/dioxane $(1: 1 \mathrm{v} / \mathrm{v})$ during $12 \mathrm{~h}$ at $45^{\circ} \mathrm{C}$. The ammonia mixture was filtered and the flask was left for 5 min under argon bubbling in order to eliminate the excess of gaseous ammonia. After solvent evaporation and drying under vacuum, the resulting products obtained with almost quantitative yields were characterized by ${ }^{1} \mathrm{H},{ }^{13} \mathrm{C}\left\{{ }^{1} \mathrm{H}\right\}$ and ${ }^{31} \mathrm{P}$ NMR and ESIMS.

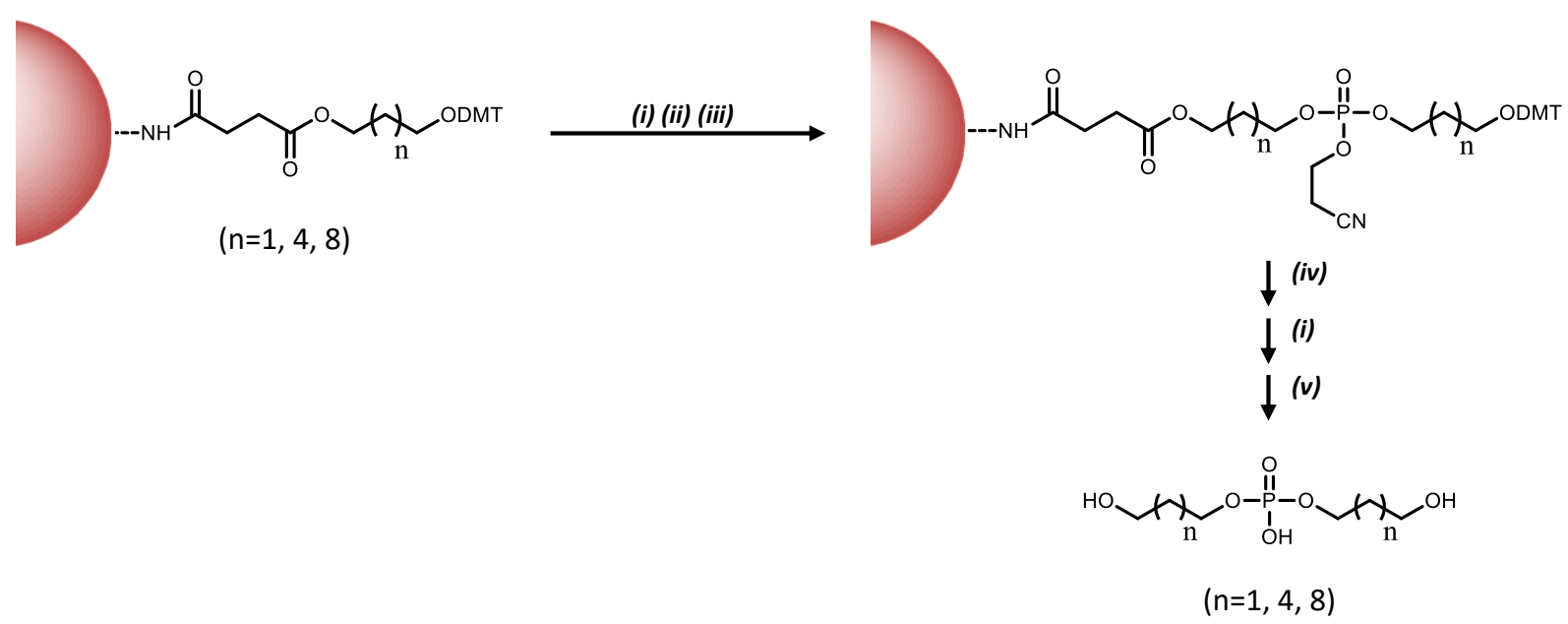

Scheme 3. Synthesis of the disubstituted phosphates. (i) DMT deprotection: $3 \% \mathrm{CCl}_{3} \mathrm{COOH}$ in $\mathrm{CH}_{2} \mathrm{Cl}_{2}$; (ii) coupling step: RT, phosphoramidite monomer, AcCN, tetrazole; (iii) oxidation: RT, $\mathrm{I}_{2}, \mathrm{H}_{2} \mathrm{O} /$ Pyridine/THF; (iv) cyanoethyl deprotection: piperidine,AcCN; (v) cleavage: $\mathrm{NH}_{3}, \mathrm{H}_{2} \mathrm{O}$, dioxane. 
Bis(3-hydroxypropyl) hydrogen phosphate. ${ }^{1} \mathrm{H}$ NMR $\left(400 \mathrm{MHz}, \mathrm{CD}_{3} \mathrm{OD}\right) \delta 3.95(\mathrm{q}, J=6.3 \mathrm{~Hz}$, 4H), $3.68(\mathrm{t}, J=6.3 \mathrm{~Hz}, 4 \mathrm{H}), 1.82(\mathrm{p}, J=6.3 \mathrm{~Hz}, 4 \mathrm{H}) .{ }^{13} \mathrm{C}\left\{{ }^{1} \mathrm{H}\right\} \mathrm{NMR}\left(100 \mathrm{MHz}, \mathrm{CD}_{3} \mathrm{OD}\right) \delta 63.2$ (d, $J=5.7 \mathrm{~Hz}), 59.5,34.7(\mathrm{~d}, J=7.2 \mathrm{~Hz}) .{ }^{31} \mathrm{P} \mathrm{NMR}\left(162 \mathrm{MHz}, \mathrm{CD}_{3} \mathrm{OD}\right) \delta 1.23 . \mathrm{HRMS}(\mathrm{ESI}) \mathrm{m} / \mathrm{z}$ : $[\mathrm{M}-\mathrm{H}]^{-}$Calcd for $\mathrm{C}_{6} \mathrm{H}_{14} \mathrm{O}_{6} \mathrm{P}^{-}$213.0533; Found 213.0531.

Bis(3-hydroxyhexyl) hydrogen phosphate. ${ }^{1} \mathrm{H}$ NMR $\left(400 \mathrm{MHz}, \mathrm{CD}_{3} \mathrm{OD}\right) \delta 3.84(\mathrm{q}, J=6.4 \mathrm{~Hz}$, 4H), $3.55(\mathrm{t}, J=6.7 \mathrm{~Hz}, 4 \mathrm{H}), 1.64(\mathrm{p}, J=6.7 \mathrm{~Hz}, 4 \mathrm{H}), 1.55(\mathrm{p}, J=6.7 \mathrm{~Hz}, 4 \mathrm{H}), 1.48-1.34(\mathrm{~m}$, 8H). ${ }^{13} \mathrm{C}\left\{{ }^{1} \mathrm{H}\right\}$ NMR $\left(100 \mathrm{MHz}, \mathrm{CD}_{3} \mathrm{OD}\right): 66.3(\mathrm{~d}, J=6.0 \mathrm{~Hz}), 62.9,33.7,31.9(\mathrm{~d}, J=7.6 \mathrm{~Hz})$, 26.8, 26.7. ${ }^{31} \mathrm{P}$ NMR (162 MHz, $\left.\mathrm{CD}_{3} \mathrm{OD}\right) \delta$ 0.96. HRMS (ESI) m/z: $[\mathrm{M}-\mathrm{H}]^{-}$Calcd for $\mathrm{C}_{12} \mathrm{H}_{26} \mathrm{O}_{6} \mathrm{P}^{-}$ 297.1472; Found 297.1468.

Bis(3-hydroxydecyl) hydrogen phosphate. ${ }^{1} \mathrm{H}$ NMR $\left(400 \mathrm{MHz}, \mathrm{CD}_{3} \mathrm{OD}\right) \delta 3.79$ (q, $J=6.4 \mathrm{~Hz}$, 4H), $3.50(\mathrm{t}, J=6.8 \mathrm{~Hz}, 4 \mathrm{H}), 1.58(\mathrm{p}, J=7.1,6.6 \mathrm{~Hz}, 4 \mathrm{H}), 1.49(\mathrm{t}, J=6.5 \mathrm{~Hz}, 4 \mathrm{H}), 1.35-1.27$ (m, 24H). ${ }^{13} \mathrm{C}\left\{{ }^{1} \mathrm{H}\right\}$ NMR $\left(100 \mathrm{MHz}, \mathrm{CD}_{3} \mathrm{OD}\right): 66.4(\mathrm{~d}, J=5.9 \mathrm{~Hz}), 63.0,33.7,31.9(\mathrm{~d}, J=7.6 \mathrm{~Hz})$, 30.7 (two carbon peaks are overlapping), 30.6, 30.5, 27.00, 26.96. ${ }^{31} \mathrm{P}$ NMR (162 MHz, CD 30 D) $\delta$ 0.97. HRMS (ESI) m/z: [M-H] $]^{-}$Calcd for $\mathrm{C}_{20} \mathrm{H}_{42} \mathrm{O}_{6} \mathrm{P}^{-}$409.2724; Found 409.2717.

S3.4 General Procedure for Preparing Phosphate Salts. The phosphate tetrabutylammonium salt was formed by titrating the corresponding acid $(1 \mathrm{mM})$ with aliquots of tetrabutylammonium hydroxide solution (1 mM) until deprotonation (Scheme 4) was complete as verified by NMR spectroscopy. The resulting tetrabutylammonium salt was concentrated in vacuo under low heat and was dried under vacuum pump overnight. 

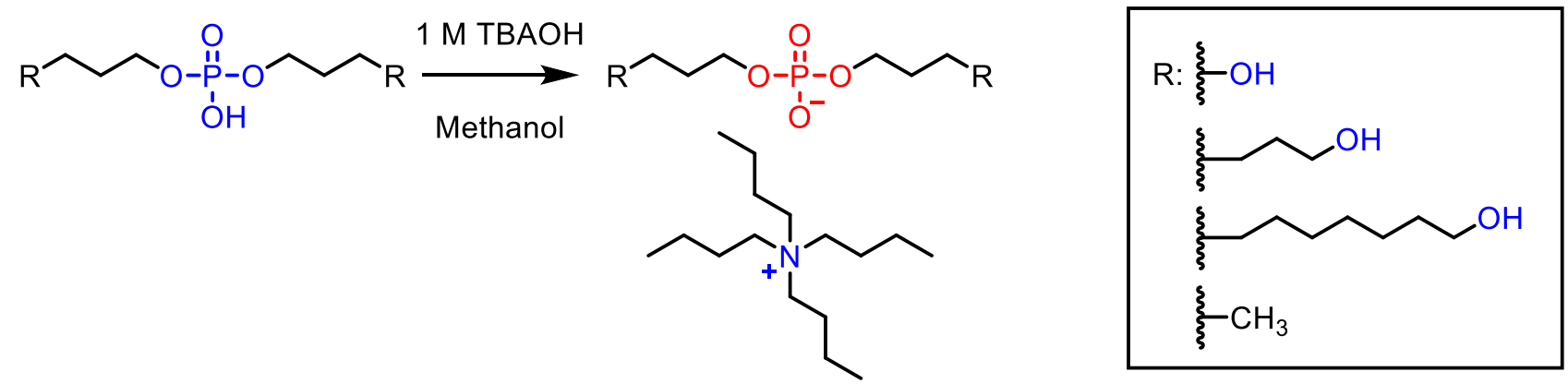

Scheme 4. Synthesis of disubstituted phosphate tetrabutylammonium salts

Preparation of the bis(3-hydroxypropyl) phosphate tetrabutylammonium salt. Dipropanol phosphate tetrabutylammonium salt was prepared using general procedure for phosphate salts from dipropanol phosphoric acid $(0.4 \mathrm{mg}, 0.0019 \mathrm{mmol})$ and tetrabutylammonium hydroxide solution (1.3 equiv., 1.1 M). Dipropanol phosphate tetrabutylammonium salt was obtained as a yellow oil (0.9 mg, $0.0020 \mathrm{mmol}$, quantitative yield). ${ }^{1} \mathrm{H} \mathrm{NMR}\left(500 \mathrm{MHz}, \mathrm{CD}_{3} \mathrm{OD}\right) \delta 3.95$ (q, $J=6.3 \mathrm{~Hz}$, 4H), $3.68(\mathrm{t}, J=6.3 \mathrm{~Hz}, 4 \mathrm{H}), 3.26-3.21(\mathrm{~m}, 10 \mathrm{H}), 1.82(\mathrm{p}, J=6.2 \mathrm{~Hz}, 4 \mathrm{H}), 1.66(\mathrm{p}, J=7.8 \mathrm{~Hz}$, $10 \mathrm{H}), 1.42(\mathrm{~m}, 10 \mathrm{H}), 1.03(\mathrm{t}, J=7.4 \mathrm{~Hz}, 15 \mathrm{H}) .{ }^{13} \mathrm{C}\left\{{ }^{1} \mathrm{H}\right\} \mathrm{NMR}\left(100 \mathrm{MHz}, \mathrm{CD}_{3} \mathrm{OD}\right) \delta 63.2(\mathrm{~d}, J=$ $5.7 \mathrm{~Hz}), 59.53,59.50,34.7(\mathrm{~d}, J=7.2 \mathrm{~Hz}), 24.8,20.7,13.9 .{ }^{31} \mathrm{P} \mathrm{NMR}\left(162 \mathrm{MHz}, \mathrm{CD}_{3} \mathrm{OD}\right) \delta 1.23$. HRMS (ESI) m/z: [M-TBA $]^{-}$Calcd $\mathrm{C}_{6} \mathrm{H}_{14} \mathrm{O}_{6} \mathrm{P}^{-}$213.0533; Found 213.0530.

Preparation of the bis(3-hydroxyhexyl) phosphate tetrabutylammonium salt. Dihexanol phosphate tetrabutylammonium salt was prepared using the general procedure for phosphate salts from dihexanol phosphoric acid (1.9 $\mathrm{mg}, 0.0064 \mathrm{mmol})$ and tetrabutylammonium hydroxide solution (1.1 equiv., 1.1 M). Dihexanol phosphate tetrabutylammonium salt was obtained was a yellow oil (4.3 mg, $0.0080 \mathrm{mmol}$, quantitative yield). ${ }^{1} \mathrm{H} \mathrm{NMR}\left(500 \mathrm{MHz}, \mathrm{CD}_{3} \mathrm{OD}\right) \delta 3.84(\mathrm{q}, J=6.4 \mathrm{~Hz}$, 4H), $3.54(\mathrm{t}, J=6.6 \mathrm{~Hz}, 4 \mathrm{H}), 3.27-3.21(\mathrm{~m}, 9 \mathrm{H}), 1.66(\mathrm{~m}, 13 \mathrm{H}), 1.55(\mathrm{p}, J=6.9 \mathrm{~Hz}, 4 \mathrm{H}), 1.42$ 
(m, 17H), $1.03(\mathrm{t}, J=7.4 \mathrm{~Hz}, 13 \mathrm{H}) .{ }^{13} \mathrm{C}\left\{{ }^{1} \mathrm{H}\right\} \mathrm{NMR}\left(100 \mathrm{MHz}, \mathrm{CD}_{3} \mathrm{OD}\right) \delta 66.3(\mathrm{~d}, J=5.8 \mathrm{~Hz})$, 62.9, 59.6 - 59.5 (m), 33.7, 31.9 (d, $J=7.6 \mathrm{~Hz}), 26.8,26.7,24.79,20.7,13.9 .{ }^{31} \mathrm{P}$ NMR (162 MHz, $\left.\mathrm{CD}_{2} \mathrm{Cl}_{2}\right) \delta$-0.36. HRMS (ESI) m/z: [M-TBA $]^{-}$Calcd for $\mathrm{C}_{12} \mathrm{H}_{26} \mathrm{O}_{6} \mathrm{P}^{-}$297.1472; Found 297.1469.

Preparation of the bis(3-hydroxydecyl) hydrogen phosphate tetrabutylammonium salt. Didecanol phosphate tetrabutylammonium salt was prepared using the general procedure for phosphate salts from didecanol phosphoric acid $(1.2 \mathrm{mg}, 0.0029 \mathrm{mmol})$ and tetrabutylammonium hydroxide solution (1.6 equiv., 1.1 M). Didecanol phosphate tetrabutylammonium salt was obtained as a white, waxy solid (2.1 mg, $0.0080 \mathrm{mmol}$, quantitative yield). ${ }^{1} \mathrm{H} \mathrm{NMR}\left(400 \mathrm{MHz}, \mathrm{CD}_{2} \mathrm{Cl}_{2}\right) \delta 3.70$ $(\mathrm{q}, J=6.7 \mathrm{~Hz}, 4 \mathrm{H}), 3.53(\mathrm{td}, J=6.8,2.0 \mathrm{~Hz}, 4 \mathrm{H}), 3.28-3.18(\mathrm{~m}, 13 \mathrm{H}), 1.63(\mathrm{p}, J=8.3 \mathrm{~Hz}, 16 \mathrm{H})$, $1.53(\mathrm{~m}, 12 \mathrm{H}), 1.42(\mathrm{~m}, 18 \mathrm{H}), 1.29$ (s, twelve ${ }^{1} \mathrm{H}$ partially overlapping with residual water peak), $1.00(\mathrm{td}, J=7.4,1.9 \mathrm{~Hz}, 19 \mathrm{H}) .{ }^{13} \mathrm{C}\left\{{ }^{1} \mathrm{H}\right\} \operatorname{NMR}\left(100 \mathrm{MHz}, \mathrm{CD}_{2} \mathrm{Cl}_{2}\right) \delta 65.1,62.7,59.2,33.3,31.44$, 31.38, 29.68, 29.66, 29.62, 26.2, 26.1, 24.4, 20.1, 13.8. ${ }^{31} \mathrm{P}$ NMR $\left(162 \mathrm{MHz}, \mathrm{CD}_{2} \mathrm{Cl}_{2}\right) \delta-0.44$. HRMS (ESI) m/z: [M-TBA $]^{-}$Calcd for $\mathrm{C}_{20} \mathrm{H}_{42} \mathrm{O}_{6} \mathrm{P}^{-}$409.2724; Found 409.2718.

Preparation of the bis(3-butyl) phosphate tetrabutylammonium salt. Dibutyl phosphate tetrabutylammonium salt was prepared using the general procedure for phosphate salts from dibutyl phosphoric acid $(75.1 \mathrm{mg}, 0.357 \mathrm{mmol})$ and tetrabutylammonium hydroxide solution (1.0 equiv., 1.1 M). Dibutyl phosphate tetrabutylammonium salt was recovered as a colorless oil (0.1758 g, 0.3892 mmol, quantitative yield). The ${ }^{1} \mathrm{H}$ NMR, ${ }^{13} \mathrm{C}\left\{{ }^{1} \mathrm{H}\right\}$ NMR, and ${ }^{31} \mathrm{P}$ NMR are consistent with previous reports. ${ }^{14}{ }^{1} \mathrm{H}$ NMR $\left(500 \mathrm{MHz}, \mathrm{CD}_{2} \mathrm{Cl}_{2}\right) \delta 3.71(\mathrm{q}, J=6.5 \mathrm{~Hz}, 4 \mathrm{H}), 3.28-$ $3.22(\mathrm{~m}, 8 \mathrm{H}), 1.62\left(\mathrm{~s}, 8{ }^{1} \mathrm{H}\right.$ partially overlapping with residual water peak), $1.58-1.51(\mathrm{~m}, 4 \mathrm{H})$, 
$1.44(\mathrm{p}, J=7.4 \mathrm{~Hz}, 8 \mathrm{H}), 1.40-1.33(\mathrm{~m}, 4 \mathrm{H}), 1.01(\mathrm{t}, J=7.3 \mathrm{~Hz}, 12 \mathrm{H}), 0.91(\mathrm{t}, J=7.4 \mathrm{~Hz}, 6 \mathrm{H})$.

${ }^{13} \mathrm{C}\left\{{ }^{1} \mathrm{H}\right\}$ NMR $\left(126 \mathrm{MHz}, \mathrm{CD}_{2} \mathrm{Cl}_{2}\right) \delta 64.81(\mathrm{~d}, J=5.8 \mathrm{~Hz}), 59.16,33.65(\mathrm{~d}, J=7.5 \mathrm{~Hz}), 24.37$,

20.12, 19.61, 14.12, 13.81. ${ }^{31} \mathrm{P}$ NMR $\left(162 \mathrm{MHz}, \mathrm{CD}_{2} \mathrm{Cl}_{2}\right) \delta-0.36 . \mathrm{HRMS}(\mathrm{ESI}) \mathrm{m} / \mathrm{z}:\left[\mathrm{M}-\mathrm{TBA}^{+}\right]^{-}$ Calcd for $\mathrm{C}_{8} \mathrm{H}_{14} \mathrm{O}_{4} \mathrm{P}^{-}$209.0948; Found 209.0946.

\section{General Procedure for Titrations}

Titrations were monitored using ${ }^{1} \mathrm{H}$ NMR spectroscopy Varian Inova $(500 \mathrm{MHz}$ and 600 MHz). Tetrabutylammonium (TBA) phosphate salts were prepared and dried under vacuum for at least 12 hours prior to use. Phosphate stock solutions were prepared immediately prior to use, and Hamilton gas tight syringes $(10,100,500$, and $1000 \mu \mathrm{L})$ were used to transfer solvents and perform titrations. NMR tubes, quartz cuvettes, and screw-cap vials were fitted with PTFE/silicone septa. In a typical ${ }^{1} \mathrm{H}$ NMR titration, a $500 \mu \mathrm{L}$ TBA phosphate solution $(1 \mathrm{mM})$ was prepared in an NMR tube and aliquots of a cyanostar solution $(50 \mathrm{mM})$ were injected into the NMR tube.

\section{X-Ray Crystallography Methods}

\section{Dipropanol Phosphate and Cyanostar in a Perched Structure}

(CCDC Deposition Number: 2034420)

Single crystals suitable for X-ray diffraction were grown by vapor diffusion of diethyl ether into a dichloromethane and acetonitrile solution. A colorless crystal (Figure S29), block, approximate dimensions $0.81 \times 0.34 \times 0.28 \mathrm{~mm}^{3}$ ) was placed onto the tip of a MiTeGen pin and mounted on a Bruker Venture D8 diffractometer equipped with a Photon III detector at $100.0 \mathrm{~K}$. 


\section{Data Collection}

The data collection was carried out using Mo $\mathrm{K} \alpha$ radiation $(\lambda=0.71073 \AA$, graphite monochromator) with a frame time of $0.50 \mathrm{~s}$ for low angle frames (2 sets) and $15 \mathrm{~s}$ for high angle frames (5 sets). The detector distance was $120 \mathrm{~mm}$. A collection strategy was calculated and complete data to a resolution of $0.70 \AA$ with a redundancy of 6 were collected. A total of 2431 frames were collected. The total exposure time was 7.18 hours. The frames were integrated with the Bruker SAINT ${ }^{117}$ software package using a narrow-frame algorithm. The integration of the data using a monoclinic unit cell yielded a total of 152650 reflections to a maximum $\theta$ angle of $30.63^{\circ}(0.70 \AA$ resolution), of which 24964 were independent (average redundancy 6.115 , completeness $\left.=99.4 \%, \mathrm{R}_{\text {int }}=12.25 \%, \mathrm{R}_{\text {sig }}=6.65 \%\right)$ and $13408(53.71 \%)$ were greater than $2 \sigma\left(\mathrm{F}^{2}\right)$. The final cell constants of $\mathrm{a}=35.5547(15) \AA, \mathrm{b}=19.4454(8) \AA, \mathrm{c}=25.5479(11) \AA, \beta$ $=112.7990(10)^{\circ}$, volume $=16283.2(12) \AA^{3}$, are based upon the refinement of the XYZ-centroids of reflections above $20 \sigma(\mathrm{I})$. Data were corrected for absorption effects using the Multi-Scan method (SADABS). ${ }^{118}$ The calculated minimum and maximum transmission coefficients (based on crystal size) are 0.9300 and 0.9750 . Additional crystal and refinement information is also included (Table S1).

\section{Structure Solution and Refinement}

The space group C 2/c was determined based on intensity statistics and systematic absences. The structure was solved using SHELXT 2014/5 ${ }^{119,120}$ and refined using full-matrix least-squares on $\mathrm{F}^{2}$ within the OLEX2 suite. ${ }^{121}$ An intrinsic phasing solution was calculated, which provided most non-hydrogen atoms from the E-map. Full-matrix least squares / difference Fourier cycles were performed, which located the remaining non-hydrogen atoms. All non-hydrogen 
atoms were refined with anisotropic displacement parameters. The hydrogen atoms were placed in ideal positions and refined as riding atoms with relative isotropic displacement parameters. The final full matrix least squares refinement converged to $\mathrm{R} 1=0.1506$ and $\mathrm{wR} 2=0.4590\left(\mathrm{~F}^{2}\right.$, all data). The goodness-of-fit was 1.519 . On the basis of the final model, the calculated density was $1.154 \mathrm{~g} / \mathrm{cm}^{3}$ and $\mathrm{F}(000), 6124 \mathrm{e}^{-}$. Whole molecule disorder on the macrocycle was modelled by dividing the occupancy into two parts related by pseudo mirror symmetry (occupancies 0.56 and 0.44). Disorder was also modelled in the tetrabuthyl ammonium and in the dipropanol phosphate. Restraints and constraints (equal thermal displacement parameters and similar distances) were applied to obtain a stable and chemically reasonable model.

\section{Dibutyl Phosphate and Cyanostar Crystal: Grown in the Presence of Methanol (CCDC Deposition Number: 2034419)}

Single crystals suitable for X-ray diffraction were grown by vapor diffusion of diethyl ether into a dichloromethane and methanol solution. A colorless crystal (Figure S35, plate, approximate dimensions $0.37 \times 0.12 \times 0.09 \mathrm{~mm}^{3}$ ) was placed onto the tip of a MiTeGen pin and mounted on a Bruker Venture D8 diffractometer equipped with a Photon III detector at $100.0 \mathrm{~K}$.

\section{Data Collection}

The data collection was carried out using Mo K $\alpha$ radiation $(\lambda=0.71073 \AA$, graphite monochromator) with a frame time of 2 seconds and a detector distance of $40 \mathrm{~mm}$. A collection strategy was calculated and complete data to a resolution of $0.77 \AA$ with a redundancy of 5 were collected. The total exposure time was 0.85 hours. The frames were integrated with the Bruker SAINT $^{117}$ software package using a narrow-frame algorithm. The integration of the data using a 
triclinic unit cell yielded a total of 91297 reflections to a maximum $\theta$ angle of $27.49^{\circ}(0.77 \AA$ resolution), of which 19782 were independent (average redundancy 4.615, completeness $=99.7 \%$, Rint $=6.83 \%$, Rsig $=5.38 \%)$ and $14266(72.12 \%)$ were greater than $2 \sigma(\mathrm{F} 2)$. The final cell constants of $\mathrm{a}=16.2873(4) \AA, \mathrm{b}=17.9403(5) \AA, \mathrm{c}=18.2427(5) \AA, \alpha=106.5390(10)^{\circ}, \beta=$ $111.7860(10)^{\circ}, \gamma=105.1800(10)^{\circ}$, volume $=4321.7(2) \AA 3$, are based upon the refinement of the XYZ-centroids of 1114 reflections above $20 \sigma(\mathrm{I})$ with $5.837^{\circ}<2 \theta<51.47^{\circ}$. Data were corrected

for absorption effects using the Multi-Scan method (SADABS). ${ }^{118}$ The ratio of minimum to maximum apparent transmission was 0.943 . The calculated minimum and maximum transmission coefficients (based on crystal size) are 0.9620 and 0.9900 . Additional crystal and refinement information is also included (Table S2).

\section{Structure Solution and Refinement}

The space group P-1 was determined based on intensity statistics and systematic absences. The structure was solved using XT (Sheldrick, 2015) $)^{119,120}$ and refined using full-matrix leastsquares on $\mathrm{F}^{2}$ within the OLEX2 suite. ${ }^{121}$ An intrinsic phasing solution was calculated, which provided most non-hydrogen atoms from the E-map. Full-matrix least squares / difference Fourier cycles were performed, which located the remaining non-hydrogen atoms. All non-hydrogen atoms were refined with anisotropic displacement parameters. The hydrogen atoms were placed in ideal positions and refined as riding atoms with relative isotropic displacement parameters. The final full matrix least squares refinement converged to $\mathrm{R} 1=0.0783$ and $w \mathrm{R} 2=0.2270\left(\mathrm{~F}^{2}\right.$, all data). The goodness-of-fit was 1.017. On the basis of the final model, the calculated density was $1.125 \mathrm{~g} / \mathrm{cm}^{3}$ and $\mathrm{F}(000), 1588 \mathrm{e}^{-}$. Whole molecule disorder on the macrocycle was modelled by dividing the occupancy into two parts related by mirror symmetry (occupancies 0.75 and 0.25 ). 
Disorder was also modelled in the tetrabutylammonium and in the dibutyl phosphate. Restraints and constraints (equal thermal displacement parameters and similar distances) were applied to obtain a stable and chemically reasonable model.

\section{Dihexanol Phosphate and Cyanostar Pseudorotaxane Crystal Structure}

\section{(CCDC Deposition Number: 2034421)}

Single crystals suitable for X-ray diffraction were grown by vapor diffusion of hexane into a 1:1 solution of dichloromethane and acetonitrile. A colourless crystal (block, approximate dimensions $0.4 \times 0.27 \times 0.23 \mathrm{~mm}^{3}$ ) was placed onto the tip of a MiTeGen pin and mounted on a Bruker Venture D8 diffractometer equipped with a PhotonIII detector at $100.0 \mathrm{~K}$.

\section{Data Collection}

The data collection was carried out using Mo K $\alpha$ radiation $(\lambda=0.71073 \AA$, graphite monochromator) with a frame time of $1 \mathrm{~s}$ for low angle scans and $25 \mathrm{~s}$ for high angle scans. The detector distance was $130 \mathrm{~mm}$. The total exposure time was 18.99 hours. The frames were integrated with the Bruker SAINT ${ }^{117}$ software package using a narrow-frame algorithm. The integration of the data using a monoclinic unit cell yielded a total of 145044 reflections to a maximum $\theta$ angle of $25.05^{\circ}(0.84 \AA$ resolution), of which 13926 were independent (average redundancy 10.415, completeness $=99.6 \%$, Rint $=12.23 \%$, Rsig $=4.80 \%)$ and $8898(63.89 \%)$ were greater than $2 \sigma(\mathrm{F} 2)$. The final cell constants of $\mathrm{a}=40.3948(13) \AA, \mathrm{b}=15.3986(5) \AA, \mathrm{c}=$ 25.9488(9) $\AA, \beta=102.2010(10)^{\circ}$, volume $=15776.2(9) \AA^{3}$, are based upon the refinement of the XYZ-centroids of 9912 reflections above $20 \sigma(\mathrm{I})$ with $4.610^{\circ}<2 \theta<46.34^{\circ}$. Data were corrected for absorption effects using the Multi-Scan method (SADABS). ${ }^{118}$ The ratio of minimum to 
maximum apparent transmission was 0.909 . The calculated minimum and maximum transmission coefficients (based on crystal size) are 0.9720 and 0.9840 . Additional crystal and refinement information is also included (Table S3).

\section{Structure Solution and Refinement}

The space group C 2/c was determined based on intensity statistics and systematic absences. The structure was solved using the SHELX suite of programs ${ }^{119,120}$ and refined using full-matrix least-squares on $\mathrm{F}^{2}$ within the OLEX2 suite. ${ }^{121}$ An intrinsic solution was calculated, which provided most non-hydrogen atoms from the E-map. Full-matrix least squares / difference Fourier cycles were performed, which located the remaining non-hydrogen atoms. All nonhydrogen atoms were refined with anisotropic displacement parameters. The hydrogen atoms were placed in ideal positions and refined as riding atoms with relative isotropic displacement parameters. The final full matrix least squares refinement converged to $\mathrm{R} 1=0.1384$ and $\mathrm{wR} 2=$

$0.4236\left(\mathrm{~F}^{2}\right.$, all data). The goodness-of-fit was 1.624 . On the basis of the final model, the calculated density was $1.035 \mathrm{~g} / \mathrm{cm}^{3}$ and $\mathrm{F}(000), 5320 \mathrm{e}^{-}$. Whole molecule disorder on the macrocycle was modelled by dividing the occupancy into two parts related by pseudo mirror symmetry (occupancies 0.73 and 0.27). Disorder over a special position was modelled for the tetrabutylammonium and the dihexanol phosphate. Restraints and constraints (equal thermal displacement parameters and similar distances) were applied to obtain a stable and chemically reasonable model. 


\section{Associated Content}

\section{Supporting Information}

The Supporting Information is available free of charge.

${ }^{1} \mathrm{H}$ NMR spectra, ${ }^{13} \mathrm{C}\left\{{ }^{1} \mathrm{H}\right\} \mathrm{c}$ NMR spectra, and ${ }^{31} \mathrm{P}$ NMR spectra, 2D NMR analysis, ${ }^{1} \mathrm{H}$ NMR titrations, computational analyses, crystallographic methods and characterizations (PDF)

Crystallographic data for cyanostar and dipropanol phosphate $\bullet$ TBA (CIF)

Crystallographic data for cyanostar and dibutyl phosphate•TBA (CIF)

Crystallographic data for cyanostar and dihexanol phosphate•TBA (CIF)

\section{Acknowledgements}

A.H.F. acknowledges support from the National Science Foundation (CHE 1709909), and R.E.F. thanks the Raymond Siedle Materials Fellowship for support and the National Institutes of Health (T32 GM109825 and T32 GM131994) for support through the training grant entitled "Graduate Program in Quantitative and Chemical Biology at Indiana University Bloomington”. Support for the acquisition of the Bruker Venture D8 diffractometer through the Major Scientific Research Equipment Fund from the President of Indiana University and the Office of the Vice President for Research is gratefully acknowledged. J.-F.L. acknowledges support from the H2020 program of the European Union (project Euro-Sequences, H2020-MSCA-ITN-2014, grant agreement $\mathrm{n}^{\circ}$ 642083) and the CNRS. J.-F.L. also thanks Laurence Oswald (Institut Charles Sadron) for the synthesis of phosphoramidite monomers and Laurence Charles (Aix Marseille Université) for the mass spectrometry characterization of the organophosphates. R.E.F. thanks Alketa Lutolli for assistance with some NMR on account of Covid-19. 


\section{References}

1. Westheimer, F., Why nature chose phosphates. Science 1987, 235, 1173-1178.

2. Busschaert, N.; Caltagirone, C.; Van Rossom, W.; Gale, P. A., Applications of Supramolecular Anion Recognition. Chem. Rev. 2015, 115, 8038-8155.

3. Hargrove, A. E.; Nieto, S.; Zhang, T.; Sessler, J. L.; Anslyn, E. V., Artificial Receptors for the Recognition of Phosphorylated Molecules. Chem. Rev. 2011, 111, 6603-6782.

4. Li, N.; Lam, W. H.; Zhai, Y.; Cheng, J.; Cheng, E.; Zhao, Y.; Gao, N.; Tye, B.-K., Structure of the origin recognition complex bound to DNA replication origin. Nature 2018, 559, 217-222.

5. Wan, L.; Essuman, K.; Anderson, R. G.; Sasaki, Y.; Monteiro, F.; Chung, E.-H.; Osborne Nishimura, E.; DiAntonio, A.; Milbrandt, J.; Dangl, J. L.; Nishimura, M. T., TIR domains of plant immune receptors are $\mathrm{NAD}^{+}$-cleaving enzymes that promote cell death. Science 2019, 365 , 799-803.

6. She, J.; Guo, J.; Chen, Q.; Zeng, W.; Jiang, Y.; Bai, X.-c., Structural insights into the voltage and phospholipid activation of the mammalian TPC1 channel. Nature 2018, 556, 130134.

7. Segawa, K.; Kurata, S.; Yanagihashi, Y.; Brummelkamp, T. R.; Matsuda, F.; Nagata, S., Caspase-mediated cleavage of phospholipid flippase for apoptotic phosphatidylserine exposure. Science 2014, 344, 1164-1168.

8. Gates, S. N.; Yokom, A. L.; Lin, J.; Jackrel, M. E.; Rizo, A. N.; Kendsersky, N. M.; Buell, C. E.; Sweeny, E. A.; Mack, K. L.; Chuang, E.; Torrente, M. P.; Su, M.; Shorter, J.; Southworth, D. R., Ratchet-like polypeptide translocation mechanism of the AAA+ disaggregase Hsp104. Science 2017, 357, 273-279.

9. Keestra-Gounder, A. M.; Byndloss, M. X.; Seyffert, N.; Young, B. M.; Chávez-Arroyo, A.; Tsai, A. Y.; Cevallos, S. A.; Winter, M. G.; Pham, O. H.; Tiffany, C. R.; de Jong, M. F.; Kerrinnes, T.; Ravindran, R.; Luciw, P. A.; McSorley, S. J.; Bäumler, A. J.; Tsolis, R. M., NOD1 and NOD2 signalling links ER stress with inflammation. Nature 2016, 532, 394-397.

10. Chu, C. T.; Ji, J.; Dagda, R. K.; Jiang, J. F.; Tyurina, Y. Y.; Kapralov, A. A.; Tyurin, V. A.; Yanamala, N.; Shrivastava, I. H.; Mohammadyani, D.; Qiang Wang, K. Z.; Zhu, J.; Klein-Seetharaman, J.; Balasubramanian, K.; Amoscato, A. A.; Borisenko, G.; Huang, Z.; Gusdon, A. M.; Cheikhi, A.; Steer, E. K.; Wang, R.; Baty, C.; Watkins, S.; Bahar, I.; Bayır, H.; Kagan, V. E., Cardiolipin externalization to the outer mitochondrial membrane acts as an elimination signal for mitophagy in neuronal cells. Nat. Cell Biol. 2013, 15, 1197-1205.

11. Lemmon, M. A., Membrane recognition by phospholipid-binding domains. Nat. Rev. Mol. Cell Biol. 2008, 9, 99-111.

12. Jayatilaka, N. K.; Restrepo, P.; Williams, L.; Ospina, M.; Valentin-Blasini, L.; Calafat, A. M., Quantification of three chlorinated dialkyl phosphates, diphenyl phosphate, 2,3,4,5tetrabromobenzoic acid, and four other organophosphates in human urine by solid phase extraction-high performance liquid chromatography-tandem mass spectrometry. Anal. Bioanal. Chem. 2017, 409, 1323-1332.

13. Yang, Z.; He, Y.; Toste, F. D., Biomimetic Approach to the Catalytic Enantioselective Synthesis of Flavonoids. J. Am. Chem. Soc. 2016, 138, 9775-9778.

14. Morton, C. M.; Zhu, Q.; Ripberger, H.; Troian-Gautier, L.; Toa, Z. S. D.; Knowles, R. R.; Alexanian, E. J., C-H Alkylation via Multisite-Proton-Coupled Electron Transfer of an Aliphatic C-H Bond. J. Am. Chem. Soc. 2019, 141, 13253-13260. 
15. Appukutti, N.; Serpell, C. J., High definition polyphosphoesters: between nucleic acids and plastics. Polym. Chem. 2018, 9, 2210-2226.

16. Vybornyi, M.; Vyborna, Y.; Häner, R., DNA-inspired oligomers: from oligophosphates to functional materials. Chem. Soc. Rev. 2019, 48, 4347-4360.

17. Al Ouahabi, A.; Charles, L.; Lutz, J.-F., Synthesis of Non-Natural Sequence-Encoded Polymers Using Phosphoramidite Chemistry. J. Am. Chem. Soc. 2015, 137, 5629-5635.

18. Al Ouahabi, A.; Kotera, M.; Charles, L.; Lutz, J.-F., Synthesis of Monodisperse SequenceCoded Polymers with Chain Lengths above DP100. ACS Macro Lett. 2015, 4, 1077-1080.

19. König, N. F.; Al Ouahabi, A.; Oswald, L.; Szweda, R.; Charles, L.; Lutz, J.-F., Photoeditable macromolecular information. Nat. Commun. 2019, 10, 3774.

20. Häner, R.; Garo, F.; Wenger, D.; Malinovskii, V. L., Oligopyrenotides: Abiotic, Polyanionic Oligomers with Nucleic Acid-like Structural Properties. J. Am. Chem. Soc. 2010, $132,7466-7471$.

21. Serpell, C. J.; Edwardson, T. G. W.; Chidchob, P.; Carneiro, K. M. M.; Sleiman, H. F., Precision Polymers and 3D DNA Nanostructures: Emergent Assemblies from New Parameter Space. J. Am. Chem. Soc. 2014, 136, 15767-15774.

22. Ziach, K.; Chollet, C.; Parissi, V.; Prabhakaran, P.; Marchivie, M.; Corvaglia, V.; Bose, P. P.; Laxmi-Reddy, K.; Godde, F.; Schmitter, J.-M.; Chaignepain, S.; Pourquier, P.; Huc, I., Single helically folded aromatic oligoamides that mimic the charge surface of double-stranded B-DNA. Nat. Chem. 2018, 10, 511-518.

23. Appukutti, N.; Jones, J. R.; Serpell, C. J., Sequence isomerism in uniform polyphosphoesters programmes self-assembly and folding. Chem. Commun. 2020, 56, 53075310 .

24. Lee, S.; Chen, C.-H.; Flood, A. H., A pentagonal cyanostar macrocycle with cyanostilbene $\mathrm{CH}$ donors binds anions and forms dialkylphosphate [3]rotaxanes. Nat. Chem. 2013, 5, 704-710. 25. Qiao, B.; Liu, Y.; Lee, S.; Pink, M.; Flood, A. H., A high-yield synthesis and acid-base response of phosphate-templated [3] rotaxanes. Chem. Commun. 2016, 52, 13675-13678.

26. Fatila, E. M.; Pink, M.; Twum, E. B.; Karty, J. A.; Flood, A. H., Phosphate-phosphate oligomerization drives higher order co-assemblies with stacks of cyanostar macrocycles. Chem. Sci. 2018, 9, 2863-2872.

27. He, Q.; Kelliher, M.; Bähring, S.; Lynch, V. M.; Sessler, J. L., A Bis-calix[4]pyrrole Enzyme Mimic That Constrains Two Oxoanions in Close Proximity. J. Am. Chem. Soc. 2017, $139,7140-7143$.

28. Choi, K.; Hamilton, A. D., Rigid Macrocyclic Triamides as Anion Receptors: AnionDependent Binding Stoichiometries and ${ }^{1} \mathrm{H}$ Chemical Shift Changes. J. Am. Chem. Soc. 2003, 125, 10241-10249.

29. Choi, K.; Hamilton, A. D., Selective Anion Binding by a Macrocycle with Convergent Hydrogen Bonding Functionality. J. Am. Chem. Soc. 2001, 123, 2456-2457.

30. Li, Y.-J.; Xu, L.; Yang, W.-L.; Liu, H.-B.; Lai, S.-W.; Che, C.-M.; Li, Y.-L., Amidetriazole: A Versatile Building Block for Construction of Oxyanion Anion Receptors. Chem. Eur. J. 2012, 18, 4782-4790.

31. Ji, X.; Guo, C.; Ke, X.-S.; Chi, X.; Sessler, J. L., Using anion recognition to control the folding and unfolding of a single chain phosphorescent polymer. Chem. Commun. 2017, 53, 8774-8777. 
32. Dietrich, B.; Hosseini, M. W.; Lehn, J. M.; Sessions, R. B., Anion receptor molecules. Synthesis and anion-binding properties of polyammonium macrocycles. J. Am. Chem. Soc. 1981, 103, 1282-1283.

33. Yu, G.; Zhou, J.; Shen, J.; Tang, G.; Huang, F., Cationic pillar[6]arene/ATP host-guest recognition: selectivity, inhibition of ATP hydrolysis, and application in multidrug resistance treatment. Chem. Sci. 2016, 7, 4073-4078.

34. Butterfield, S. M.; Waters, M. L., A Designed $\beta$-Hairpin Peptide for Molecular Recognition of ATP in Water. J. Am. Chem. Soc. 2003, 125, 9580-9581.

35. Galan, A.; De Mendoza, J.; Toiron, C.; Bruix, M.; Deslongchamps, G.; Rebek, J., A synthetic receptor for dinucleotides. J. Am. Chem. Soc. 1991, 113, 9424-9425.

36. Kato, Y.; Conn, M. M.; Rebek, J., Jr., Water-Soluble Receptors for Cyclic-AMP and Their Use for Evaluating Phosphate-Guanidinium Interactions. J. Am. Chem. Soc. 1994, 116, 32793284.

37. McCleskey, S. C.; Griffin, M. J.; Schneider, S. E.; McDevitt, J. T.; Anslyn, E. V., Differential Receptors Create Patterns Diagnostic for ATP and GTP. J. Am. Chem. Soc. 2003, $125,1114-1115$.

38. Hoffman, J. L.; Bock, R. M., Interaction of cyclodextrins with nucleic acids. A study of secondary structure in three transfer ribonucleic acids. Biochemistry 1970, 9, 3542-3550. 39. Kimura, E.; Kodama, M.; Yatsunami, T., Macromonocyclic polyamines as biological polyanion complexons. 2. Ion-pair association with phosphate and nucleotides. J. Am. Chem. Soc. 1982, 104, 3182-3187.

40. Lee, M.; Moon, J. H.; Jun, E. J.; Kim, G.; Kwon, Y.-U.; Lee, J. Y.; Yoon, J., A tetranaphthoimidazolium receptor as a fluorescent chemosensor for phytate. Chem. Commun. 2014, 50, 5851-5853.

41. Reinmuth, M.; Pramanik, S.; Douglas, J. T.; Day, V. W.; Bowman-James, K., Structural Impact of Chelation on Phytate, a Highly Phosphorylated Biomolecule. Eur. J. Inorg. Chem. 2019, 2019, 1870-1874.

42. Pramanik, S.; Day, V. W.; Bowman-James, K., Supramolecular traps for highly phosphorylated inositol sources of phosphorus. Chem. Commun. 2020, 56, 3269-3272.

43. Ji, X.; Wu, R.-T.; Long, L.; Guo, C.; Khashab, N. M.; Huang, F.; Sessler, J. L., Physical Removal of Anions from Aqueous Media by Means of a Macrocycle-Containing Polymeric Network. J. Am. Chem. Soc. 2018, 140, 2777-2780.

44. Taylor, C. G. P.; Metherell, A. J.; Argent, S. P.; Ashour, F. M.; Williams, N. H.; Ward, M. D., Coordination-Cage-Catalysed Hydrolysis of Organophosphates: Cavity- or SurfaceBased? Chem. Eur. J. 2020, 26, 3065-3073.

45. Liu, Y.; Bonizzoni, M., A Supramolecular Sensing Array for Qualitative and Quantitative Analysis of Organophosphates in Water. J. Am. Chem. Soc. 2014, 136, 14223-14229.

46. Bolliger, J. L.; Belenguer, A. M.; Nitschke, J. R., Enantiopure Water-Soluble [Fe $\left.\mathrm{FL}_{6}\right]$ Cages: Host-Guest Chemistry and Catalytic Activity. Angew. Chem. Int. Ed. 2013, 52, 79587962.

47. Sun, X.; Dahlhauser, S. D.; Anslyn, E. V., New Autoinductive Cascade for the Optical Sensing of Fluoride: Application in the Detection of Phosphoryl Fluoride Nerve Agents. J. Am. Chem. Soc. 2017, 139, 4635-4638.

48. Sun, X.; Boulgakov, A. A.; Smith, L. N.; Metola, P.; Marcotte, E. M.; Anslyn, E. V., Photography Coupled with Self-Propagating Chemical Cascades: Differentiation and 
Quantitation of G- and V-Nerve Agent Mimics via Chromaticity. ACS Cent. Sci. 2018, 4, 854861.

49. Sun, X.; Reuther, J. F.; Phillips, S. T.; Anslyn, E. V., Coupling Activity-Based Detection, Target Amplification, Colorimetric and Fluorometric Signal Amplification, for Quantitative Chemosensing of Fluoride Generated from Nerve Agents. Chem. Eur. J. 2017, 23, 3903-3909. 50. Hiscock, J. R.; Wells, N. J.; Ede, J. A.; Gale, P. A.; Sambrook, M. R., Biasing hydrogen bond donating host systems towards chemical warfare agent recognition. Org. Biomol. Chem. 2016, 14, 9560-9567.

51. Watanabe, S.; Onogawa, O.; Komatsu, Y.; Yoshida, K., Luminescent Metalloreceptor with a Neutral Bis(Acylaminoimidazoline) Binding Site: Optical Sensing of Anionic and Neural Phosphodiesters. J. Am. Chem. Soc. 1998, 120, 229-230.

52. Ojida, A.; Mito-oka, Y.; Sada, K.; Hamachi, I., Molecular Recognition and Fluorescence Sensing of Monophosphorylated Peptides in Aqueous Solution by Bis(zinc(II)-dipicolylamine)Based Artificial Receptors. J. Am. Chem. Soc. 2004, 126, 2454-2463.

53. Chin, J.; Chung, S.; Kim, D. H., Synergistic Effect between Metal Coordination and Hydrogen Bonding in Phosphate and Halide Recognition. J. Am. Chem. Soc. 2002, 124, 1094810949.

54. Kneeland, D. M.; Ariga, K.; Lynch, V. M.; Huang, C. Y.; Anslyn, E. V.,

Bis(alkylguanidinium) receptors for phosphodiesters: effect of counterions, solvent mixtures, and cavity flexibility on complexation. J. Am. Chem. Soc. 1993, 115, 10042-10055.

55. Dixon, R. P.; Geib, S. J.; Hamilton, A. D., Molecular recognition: bis-acylguanidiniums provide a simple family of receptors for phosphodiesters. J. Am. Chem. Soc. 1992, 114, 365-366. 56. Szweda, R.; Tschopp, M.; Felix, O.; Decher, G.; Lutz, J.-F., Sequences of Sequences: Spatial Organization of Coded Matter through Layer-by-Layer Assembly of Digital Polymers. Angew. Chem. Int. Ed. 2018, 57, 15817-15821.

57. Cavallo, G.; Poyer, S.; Amalian, J.-A.; Dufour, F.; Burel, A.; Carapito, C.; Charles, L.; Lutz, J.-F., Cleavable Binary Dyads: Simplifying Data Extraction and Increasing Storage Density in Digital Polymers. Angew. Chem. Int. Ed. 2018, 57, 6266-6269.

58. König, N. F.; Al Ouahabi, A.; Poyer, S.; Charles, L.; Lutz, J.-F., A Simple PostPolymerization Modification Method for Controlling Side-Chain Information in Digital Polymers. Angew. Chem. Int. Ed. 2017, 56, 7297-7301.

59. Illuminati, G.; Mandolini, L., Ring closure reactions of bifunctional chain molecules. Acc. Chem. Res. 1981, 14, 95-102.

60. Lightstone, F. C.; Bruice, T. C., Enthalpy and Entropy in Ring Closure Reactions. Bioorg. Chem. 1998, 26, 193-199.

61. Fenniri, H.; Deng, B.-L.; Ribbe, A. E.; Hallenga, K.; Jacob, J.; Thiyagarajan, P., Entropically driven self-assembly of multichannel rosette nanotubes. Proc. Natl. Acad. Sci. 2002, 99, 6487-6492.

62. Král, V.; Furuta, H.; Shreder, K.; Lynch, V.; Sessler, J. L., Protonated Sapphyrins. Highly Effective Phosphate Receptors. J. Am. Chem. Soc. 1996, 118, 1595-1607.

63. Zhao, W.; Qiao, B.; Chen, C.-H.; Flood, A. H., High-Fidelity Multistate Switching with Anion-Anion and Acid-Anion Dimers of Organophosphates in Cyanostar Complexes. Angew. Chem. Int. Ed. 2017, 56, 13083-13087.

64. Zhao, W.; Flood, A. H.; White, N. G., Recognition and applications of anion-anion dimers based on anti-electrostatic hydrogen bonds (AEHBs). Chem. Soc. Rev. 2020. 
65. Svec, J.; Necas, M.; Sindelar, V., Bambus[6]uril. Angew. Chem. Int. Ed. 2010, 49, 23782381.

66. Fiala, T.; Sindelar, V., Supramolecular complexes of bambusurils with dialkyl phosphates. Supramol. Chem. 2016, 28, 810-816.

67. Langston, P. K.; Nambu, A.; Jung, J.; Shibata, M.; Aksoylar, H. I.; Lei, J.; Xu, P.; Doan, M. T.; Jiang, H.; MacArthur, M. R.; Gao, X.; Kong, Y.; Chouchani, E. T.; Locasale, J. W.; Snyder, N. W.; Horng, T., Glycerol phosphate shuttle enzyme GPD2 regulates macrophage inflammatory responses. Nature Immunology 2019, 20, 1186-1195.

68. Lamosa, P.; Turner, D. L.; Ventura, R.; Maycock, C.; Santos, H., Protein stabilization by compatible solutes. FEBS J. 2003, 270, 4606-4614.

69. Martins, L. O.; Huber, R.; Huber, H.; Stetter, K. O.; Da Costa, M. S.; Santos, H., Organic solutes in hyperthermophilic archaea. Appl. Environ. Microbiol. 1997, 63, 896-902.

70. Jubian, V.; Veronese, A.; Dixon, R. P.; Hamilton, A. D., Acceleration of a Phosphate Diester Transesterification Reaction by Bis(alkylguanidinium) Receptors Containing an Appended General Base. Angew. Chem. Int. Ed. Engl. 1995, 34, 1237-1239.

71. Suh, J.; Hong, S. H., Catalytic Activity of Ni(II)-Terpyridine Complex in Phosphodiester Transesterification Remarkably Enhanced by Self-Assembly of Terpyridines on Poly(ethylenimine). J. Am. Chem. Soc. 1998, 120, 12545-12552.

72. Tjioe, L.; Joshi, T.; Brugger, J.; Graham, B.; Spiccia, L., Synthesis, Structure, and DNA Cleavage Properties of Copper(II) Complexes of 1,4,7-Triazacyclononane Ligands Featuring Pairs of Guanidine Pendants. Inorg. Chem. 2011, 50, 621-635.

73. Liu, S.; Hamilton, A. D., Catalysis of phosphodiester transesterification by dinuclear $\mathrm{Cu}(\mathrm{II})$ complexes: The role of the second Cu(II) ion. Bioorg. Med. Chem. Lett. 1997, 7, 1779-1784.

74. Williams, N. H.; Chin, J., Metal-ion catalysed phosphate diester transesterification: quantifying double Lewis-acid activation. Chem. Commun. 1996, 131-132.

75. Jeffrey, G. A., An introduction to hydrogen bonding. Oxford University Press, New York: 1997; Vol. 32.

76. White, N. G.; MacLachlan, M. J., Anion-templated hexagonal nanotubes. Chem. Sci. 2015, 6, 6245-6249.

77. White, N. G.; Carta, V.; MacLachlan, M. J., Layered 2D Sheetlike Supramolecular Polymers Formed by O-H...Anion Hydrogen Bonds. Cryst. Growth Des. 2015, 15, 1540-1545. 78. Morshedi, M.; Boer, S. A.; Thomas, M.; White, N. G., Easily-prepared Hydroxy-containing Receptors Recognize Anions in Aqueous Media. Chem. Asian J. 2019, 14, 1271-1277. 79. Heid, C.; Sowislok, A.; Schaller, T.; Niemeyer, F.; Klärner, F.-G.; Schrader, T., Molecular Tweezers with Additional Recognition Sites. Chem. Eur. J. 2018, 24, 11332-11343. 80. de Jong, J.; Feringa, B. L.; Wezenberg, S. J., Light-Modulated Self-Blockage of a Urea Binding Site in a Stiff-Stilbene Based Anion Receptor. ChemPhysChem 2019, 20, 3306-3310. 81. Gale, P. A.; Hiscock, J. R.; Moore, S. J.; Caltagirone, C.; Hursthouse, M. B.; Light, M. E., Anion-Anion Proton Transfer in Hydrogen Bonded Complexes. Chem. Asian J. 2010, 5, 555561.

82. Boer, S. A.; Foyle, E. M.; Thomas, C. M.; White, N. G., Anion coordination chemistry using O-H groups. Chem. Soc. Rev. 2019, 48, 2596-2614.

83. Zhao, J.; Yang, D.; Yang, X.-J.; Wu, B., Anion coordination chemistry: From recognition to supramolecular assembly. Coord. Chem. Rev. 2019, 378, 415-444.

84. Parmar, D.; Sugiono, E.; Raja, S.; Rueping, M., Complete Field Guide to Asymmetric BINOL-Phosphate Derived Brønsted Acid and Metal Catalysis: History and Classification by 
Mode of Activation; Brønsted Acidity, Hydrogen Bonding, Ion Pairing, and Metal Phosphates. Chem. Rev. 2014, 114, 9047-9153.

85. Pitt, J. N.; Ferré-D’Amaré, A. R., Structure-Guided Engineering of the Regioselectivity of RNA Ligase Ribozymes. J. Am. Chem. Soc. 2009, 131, 3532-3540.

86. Elias, M.; Wellner, A.; Goldin-Azulay, K.; Chabriere, E.; Vorholt, J. A.; Erb, T. J.;

Tawfik, D. S., The molecular basis of phosphate discrimination in arsenate-rich environments. Nature 2012, 491, 134-137.

87. Phipps, R. J.; Toste, F. D., Chiral Anion Phase-Transfer Catalysis Applied to the Direct

Enantioselective Fluorinative Dearomatization of Phenols. J. Am. Chem. Soc. 2013, 135, 12681271.

88. Egli, M.; Usman, N.; Rich, A., Conformational influence of the ribose 2'-hydroxyl group: Crystal structures of DNA-RNA chimeric duplexes. Biochemistry 1993, 32, 3221-3237.

89. Bah, A.; Vernon, R. M.; Siddiqui, Z.; Krzeminski, M.; Muhandiram, R.; Zhao, C.;

Sonenberg, N.; Kay, L. E.; Forman-Kay, J. D., Folding of an intrinsically disordered protein by phosphorylation as a regulatory switch. Nature 2015, 519, 106-109.

90. Jeppesen, J. O.; Vignon, S. A.; Stoddart, J. F., In the Twilight Zone between

[2]Pseudorotaxanes and [2]Rotaxanes. Chem. Eur. J. 2003, 9, 4611-4625.

91. Nygaard, S.; Leung, K. C. F.; Aprahamian, I.; Ikeda, T.; Saha, S.; Laursen, B. W.; Kim, S.-Y.; Hansen, S. W.; Stein, P. C.; Flood, A. H.; Stoddart, J. F.; Jeppesen, J. O., Functionally Rigid Bistable [2]Rotaxanes. J. Am. Chem. Soc. 2007, 129, 960-970.

92. Nygaard, S.; Hansen, C. N.; Jeppesen, J. O., Binding Studies between Triethylene GlycolSubstituted Monopyrrolotetrathiafulvalene Derivatives and Cyclobis(paraquat-p-phenylene). $J$. Org. Chem. 2007, 72, 1617-1626.

93. Barfield, M., Structural Dependencies of Interresidue Scalar Coupling h3JNC` and Donor 1H Chemical Shifts in the Hydrogen Bonding Regions of Proteins. J. Am. Chem. Soc. 2002, 124, 4158-4168.

94. Karplus, M., Contact electron - spin coupling of nuclear magnetic moments. J. Chem. Phys. 1959, 30, 11-15.

95. Farès, C.; Hassfeld, J.; Menche, D.; Carlomagno, T., Simultaneous Determination of the Conformation and Relative Configuration of Archazolide A by Using Nuclear Overhauser Effects, J Couplings, and Residual Dipolar Couplings. Angew. Chem. Int. Ed. 2008, 47, 37223726.

96. Markwick, P. R. L.; Sprangers, R.; Sattler, M., Dynamic Effects on J-Couplings Across Hydrogen Bonds in Proteins. J. Am. Chem. Soc. 2003, 125, 644-645.

97. Baldwin, J. E., Rules for ring closure. J. Chem. Soc., Chem. Commun. 1976, 734-736.

98. Page, M. I.; Jencks, W. P., Entropic Contributions to Rate Accelerations in Enzymic and Intramolecular Reactions and the Chelate Effect. Proc. Natl. Acad. Sci. 1971, 68, 1678-1683. 99. Martí-Centelles, V.; Pandey, M. D.; Burguete, M. I.; Luis, S. V., Macrocyclization Reactions: The Importance of Conformational, Configurational, and Template-Induced Preorganization. Chem. Rev. 2015, 115, 8736-8834.

100. Hua, Y.; Ramabhadran, R. O.; Uduehi, E. O.; Karty, J. A.; Raghavachari, K.; Flood, A. H., Aromatic and Aliphatic CH Hydrogen Bonds Fight for Chloride while Competing Alongside Ion Pairing within Triazolophanes. Chem. Eur. J. 2011, 17, 312-321.

101. Qiao, B.; Anderson, J. R.; Pink, M.; Flood, A. H., Size-matched recognition of large anions by cyanostar macrocycles is saved when solvent-bias is avoided. Chem. Commun. 2016, $52,8683-8686$. 
102. Zahran, E. M.; Fatila, E. M.; Chen, C.-H.; Flood, A. H.; Bachas, L. G., Cyanostar: C-H Hydrogen Bonding Neutral Carrier Scaffold for Anion-Selective Sensors. Anal. Chem. 2018, 90, 1925-1933.

103. Batsanov, S. S., Van der Waals Radii of Elements. Inorg. Mater. 2001, 37, 871-885.

104. Zhao, W.; Tropp, J.; Qiao, B.; Pink, M.; Azoulay, J. D.; Flood, A. H., Tunable Adhesion from Stoichiometry-Controlled and Sequence-Defined Supramolecular Polymers Emerges Hierarchically from Cyanostar-Stabilized Anion-Anion Linkages. J. Am. Chem. Soc. 2020, 142, 2579-2591.

105. He, Q.; Tu, P.; Sessler, J. L., Supramolecular Chemistry of Anionic Dimers, Trimers, Tetramers, and Clusters. Chem 2018, 4, 46-93.

106. Casadei, M. A.; Galli, C.; Mandolini, L., Ring-Closure Reactions. 22. Kinetics of Cyclization of Diethyl ( $\omega$-Bromoalkyl)malonates in the Range of 4- to 21-membered rings. Role of Ring Strain. J. Am. Chem. Soc. 1984, 106, 1051-1056.

107. Mandolini, L., Ring-Closure Reactions. 11. The Activation Parameters for the Formation of Four- to Six-Membered Lactones from $\omega$-Bromoalkanoate Ions. The Role of the Entropy Factor in Small- and Common-Ring Formation. J. Am. Chem. Soc. 1978, 100, 550-554.

108. Galli, C.; Illuminati, G.; Mandolini, L.; Tamborra, P., Ring-Closure Reactions. 7. Kinetics and Activation Parameters of Lactone Formation in the Range of 3- to 23-Membered Rings. J. Am. Chem. Soc. 1977, 99, 2591-2597.

109. Avakyan, N.; Greschner, A. A.; Aldaye, F.; Serpell, C. J.; Toader, V.; Petitjean, A.; Sleiman, H. F., Reprogramming the assembly of unmodified DNA with a small molecule. Nat. Chem. 2016, 8, 368-376.

110. Langton, M. J.; Serpell, C. J.; Beer, P. D., Anion Recognition in Water: Recent Advances from a Supramolecular and Macromolecular Perspective. Angew. Chem. Int. Ed. 2016, 55, 19741987.

111. Hua, Y.; Liu, Y.; Chen, C.-H.; Flood, A. H., Hydrophobic Collapse of Foldamer Capsules Drives Picomolar-Level Chloride Binding in Aqueous Acetonitrile Solutions. J. Am. Chem. Soc. 2013, 135, 14401-14412.

112. Liu, Y.; Parks, F. C.; Sheetz, E. G.; Chen, C.-H.; Flood, A. H., Polarity-Tolerant Chloride Binding in Foldamer Capsules by Programmed Solvent-Exclusion. J. Am. Chem. Soc. 2021, 143, 3191-3204.

113. Bordwell, F. G.; McCallum, R. J.; Olmstead, W. N., Acidities and hydrogen bonding of phenols in dimethyl sulfoxide. J. Org. Chem. 1984, 49, 1424-1427.

114. Olmstead, W. N.; Margolin, Z.; Bordwell, F. G., Acidities of water and simple alcohols in dimethyl sulfoxide solution. J. Org. Chem. 1980, 45, 3295-3299.

115. Horne, W. S.; Gellman, S. H., Foldamers with Heterogeneous Backbones. Acc. Chem. Res. 2008, 41, 1399-1408.

116. McConnell, A. J.; Serpell, C. J.; Thompson, A. L.; Allan, D. R.; Beer, P. D., Calix[4]arene-Based Rotaxane Host Systems for Anion Recognition. Chem. Eur. J. 2010, 16, 1256-1264.

117. SAINT, V8.30A, Bruker Analytical X-ray Systems, Madison, WI. 2012.

118. SADABS, 2.03, Bruker Analytical X-ray Systems, Madison, WI. 2016.

119. Sheldrick, G., A short history of SHELX. Acta Cryst. 2008, 64, 112-122.

120. Sheldrick, G., SHELXT - Integrated space-group and crystal-structure determination. Acta Cryst. 2015, 71, 3-8. 
121. Dolomanov, O. V.; Bourhis, L. J.; Gildea, R. J.; Howard, J. A. K.; Puschmann, H., OLEX2: a complete structure solution, refinement and analysis program. J. Appl. Crystallogr. 2009, 42, 339-341. 